\title{
Cenários do Debate sobre a Natureza da Ciência nos Cursos de Licenciatura em Física no Brasil ${ }^{+*}$
}

\author{
Gabriela Kaiana Ferreira ${ }^{1}$ \\ José Francisco Custódio ${ }^{1}$ \\ Departamento de Física - Universidade Federal de Santa Catarina \\ Florianópolis - SC
}

\section{Resumo}

Neste trabalho tivemos o objetivo de investigar a dimensão da inserção de reflexões sobre a natureza da ciência e que aspectos da natureza da ciência são privilegiados em cursos de Licenciatura em Física (LF) de instituições de Ensino Superior (IES) públicas no Brasil. Com auxílio da Análise de Conteúdo, identificamos e analisamos ementas de 390 disciplinas que tratavam do tema presentes nos Projetos Pedagógicos de Curso e Matrizes Curriculares de 145 cursos de LF de 90 IES. Evidenciamos que a inserção de temas relativos à natureza da ciência é muito tímida nos cursos de LF, inseridas em disciplinas que representam apenas 4,65\% da carga horária dos cursos, classificadas nesta pesquisa como Saberes Disciplinares de História, Filosofia, Epistemologia e Sociologia da(s) Ciência(s) e da Física (3,39\%), Saberes Pedagógicos (0,94\%) e Saberes Disciplinares de Física (0,32\%). Além disso, as ementas foram categorizadas a partir de diferentes abordagens com relação a abrangência e profundidade do conteúdo histórico, filosófico, epistemológico e sociológico da ciência/física, e do ensino da natureza da ciência. Concluímos que há certa influência das recomendações da área de educação científica sobre o tema natureza da ciência nos currículos de LF, bem como diversidade de aspectos da natureza da ciência sendo abordados, indicando falta de consenso sobre o que deve ser ensinado.

\footnotetext{
${ }^{+}$Scenarios of the Debate about the Nature of Science in Physics Degree Courses in Brazil

* Recebido: 20 de maio de 2020.

Aceito: 2 de junho de 2021.

${ }^{1}$ E-mails: gabriela.kaiana@ufsc.br; j.custodio@ufsc.br
} 
Palavras-chave: Natureza da Ciência; Formação de Professores; Saberes Docentes.

\begin{abstract}
In this paper we aimed to map the offer of subjects with discussions on the Nature of Science in undergraduate Physics courses from public higher education institutions in Brazil. For this, we developed a documental analysis of 390 subject's syllabuses present in the Pedagogical Course Projects of 145 undergraduate Physics course of 90 public higher education institutions, with discussions related to the Nature of Science. From the results, despite what is indicated in guiding and legislative documents encouraging this type of discussion, we conclude that the scheduled time for subject's syllabuses addressing the Nature of Science, even if briefly, is still very low (discussions are contemplated in disciplines that add up to a scheduled time of $4.65 \%$ of the total scheduled time of undergraduate courses). In the analysis, the subject's syllabuses were classified according to the notion of Teaching Knowledge encompassing Disciplinary Knowledge of History, Philosophy, Epistemology and Sociology of Sciences and Physics, Pedagogical Knowledge and Disciplinary Knowledge of Physics. Furthermore, concerning the discussion of the Nature of Science, the subject's syllabuses were categorized based on different approaches regarding the scope and depth of the historical, philosophical, epistemological, and sociological content of Science and Physics. In summary, we conclude that there is some influence of research in science education in the recommendations on teaching the nature of science in $L F$ curricula, in the diversity of aspects of the nature of science being addressed, indicating a lack of consensus on what should be taught.
\end{abstract}

Keywords: Nature of Science; Physics Teacher Training; Teaching Knowledge.

\title{
I. Introdução
}

$\mathrm{Na}$ educação científica há uma preocupação e defesa por parte de professores e pesquisadores por um ensino que possibilite a compreensão da natureza da ciência e dos princípios da pesquisa científica que levem em consideração aspectos essenciais como a finalidade do trabalho científico, a natureza do conhecimento científico e a ideia de que a ciência é um empreendimento social, valorizando, portanto, a percepção sobre ciências como 
uma atividade humana, permeada e condicionada por valores éticos, econômicos, políticos, culturais (MATTHEWS, 1995; HARRES, 1999; GIL-PÉREZ et al., 2001; DUARTE, 2004; SCHWARTZ; LEDERMAN; CRAWFORD, 2004; EL-HANI, 2006; MARTINS, 2007; LEDERMAN, 2007; PEREIRA; MARTINS, 2011; McCOMAS, 2017). Para além de definições e relações básicas da ciência, defende-se a importância de se conhecer o campo de validade, as justificativas, as circunstâncias em que determinado conhecimento pode ser enfraquecido ou mesmo rejeitado. Isto inclui o ensino e aprendizagem da natureza da ciência que vislumbrem como objetivos a compreensão, por parte de toda a comunidade, de como a ciência gera conhecimento a partir de processos filosóficos aceitáveis na prática da ciência, e sobre os produtos filosóficos da ciência (McCOMAS, 2017).

Há mais de duas décadas, Carvalho e Vannucchi (1995) e Matthews (1994) já sinalizavam que temas emergentes em filosofia, história e epistemologia da ciência contribuem na construção de uma imagem mais rica e valorativa da ciência, quando são adequadamente apropriados por professores de ciências em formação e em exercício. Todavia, a formação de professores ainda parece ser imprecisa e ineficaz no que se refere à natureza da ciência. Recentemente, Clough (2018) destacou que poucos programas de formação de professores de ciências exigem qualquer curso em história e natureza da ciência. Além disso, existe muito pouco tempo nos cursos sobre o processo de construção do conhecimento científico para promover um entendimento profundo e robusto da natureza da ciência e da natureza da ciência como objeto de ensino, bem como para preparar os professores para as fortes restrições institucionais que eles possam enfrentar tentando ensinar sobre a história e a natureza da ciência.

Neste sentido, Forato, Pietrocola e Martins (2011), apresentam uma síntese de obstáculos, tensões e dilemas inevitáveis e riscos decorrentes do processo de inserção de discussões sobre a natureza da ciência e do uso da história e filosofia da ciência no ensino de ciências. Forato, Pietrocola e Martins (2011, p. 35-36), argumentam que:

\footnotetext{
Qualquer narrativa da HC traz, implícita ou explicitamente, os valores, as crenças e as orientações metodológicas do seu autor. O relato histórico da criação de um conceito cientifico, ou de um debate entre teorias rivais, ou da realização de experimentos, por exemplo, carregam concepções sobre a natureza da ciência e sobre os processos da sua construção. Não é possivel separar essas concepçães pessoais (em maior ou menor grau) do trabalho de qualquer profissional ligado à ciência, inclusive do historiador da ciência.
}

Com efeito, a literatura tem mostrado que professores de ciência de todos os níveis simplesmente não entendem a natureza da ciência como fazem com o conteúdo mais tradicional. Além disso, os professores não sabem como incluí-la na instrução (McCOMAS; NOURI, 2016). É evidente que a falta de formação específica do professor consiste em um dos grandes desafios a serem enfrentados na didatização da história da ciência e natureza da ciência em sala de aula (FORATO; PIETROCOLA; MARTINS, 2011). Assim, para que seja 
promovida significativa e adequada instrução sobre a natureza da ciência na Educação Básica, os programas de formação de professores devem salientar a natureza da ciência tanto na formação inicial quanto no desenvolvimento profissional.

Atualmente, os cursos de licenciatura das áreas das ciências no Brasil, inclusive de Licenciatura em Física (LF), têm contemplado esta temática, reservando espaço para disciplinas de caráter histórico e/ou filosófico (STAUB DE MELO, 2005; MARTINS, 2007; 2015; MOREIRA; MASSONI; OSTERMANN, 2007, ROSA; MARTINS, 2007; PEREIRA; MARTINS, 2011; FERREIRA; MARTINS, 2012; NICOLODELLI, 2011; ALMEIDA; FARIAS, 2011; FORATO; PIETROCOLA; MARTINS, 2011; RAPOSO, 2014; FERREIRA; CUSTÓDIO, 2017; FERREIRA, 2018). Essas disciplinas, propostas com a intenção de tangenciar minimamente essa necessidade formativa dos professores, em alguma medida, refletem sobre suas práticas de sala de aula, pois, ainda que implicitamente, podem orientar as decisões dos professores sobre o que ensinar, como ensinar e para que ensinar de e sobre ciências/física.

A inserção nos cursos de LF do debate sobre a natureza da ciência também é incentivada e respaldada pela legislação e orientações para o Ensino Superior (BRASIL, 2001a, 2001b, 2015) e para a Educação Básica (BRASIL, 2013). Geralmente, os documentos oficiais mencionam a necessidade de se trabalhar questões relacionadas à gnosiologia e epistemologia do conhecimento científico. Neste sentido, algumas orientações para a formação de professores de ciências, o que inclui a formação de professores de física, indicam como competência e habilidade geral: "Desenvolver uma ética de atuação profissional e a consequente responsabilidade social, compreendendo a Ciência como conhecimento histórico, desenvolvido em diferentes contextos sociopolíticos, culturais e econômicos." (BRASIL, 2001 b, p. 4, destaque nosso). Isto ocorreria por meio de disciplinas complementares que tenham como função ampliar a educação do formando, abrangendo "outras ciências naturais e também as ciências humanas contemplando questões como Ética, Filosofia e História da Ciência, Gerenciamento e Política Científica, etc." (BRASIL, 2001b, p. 7, destaque nosso). Mas, embora os documentos legais mencionem a importância formativa da natureza da ciência, geralmente o fazem de forma superficial e não oferecem subsídios para implementação, ou dimensionamento no currículo, de aspectos sobre filosofia e história da ciência.

Tendo em vista este panorama, pesquisas têm sido realizadas com o objetivo de compreender como se estruturam e desenvolvem discussões sobre a natureza da ciência em cursos de formação inicial de professores na área da educação em ciências. Por exemplo, Pereira e Martins (2011) investigaram a estrutura curricular dos cursos de Licenciatura em Física e em Química da UFRN no que se refere à inserção de disciplinas de conteúdo histórico e filosófico. Os autores analisaram documentos como os PPC, programas de disciplinas de conteúdo histórico e filosófico, entre outros materiais, além de realizarem observações e entrevistas com os professores responsáveis pelas disciplinas de história da 
física e história da química. Para os autores, o fato de as disciplinas com enfoque histórico e filosófico da ciência serem ofertadas nas últimas fases do curso pode estar associado a modelos formativos de currículos fragmentados e dissociados da realidade profissional, tendo em vista que "a valorização das disciplinas de conteúdo específico das áreas [...] deixa em segundo plano as demais disciplinas curriculares, como as de conteúdo pedagógico e as de natureza interdisciplinar [...]." (PEREIRA; MARTINS, 2011, p. 238). Com relação ao enfoque teórico das ementas e dos conteúdos programáticos, evidenciaram diferentes perspectivas. Na LF, o enfoque teórico prioriza uma discussão sobre a natureza da ciência, isto é, uma visão externalista da história da ciência, enquanto na Licenciatura em Química, o enfoque teórico prioriza uma discussão pautada em elementos da história conceitual da química, isto é, uma visão internalista da história da ciência.

Rosa e Martins (2007) investigaram a inserção da história e filosofia da ciência no currículo de formação de professores de física da UFBA, analisando matrizes curriculares e ementas, bem como a percepção dos professores dos cursos de LF da instituição, por meio de pesquisa documental e entrevistas semiestruturadas com os docentes. As autoras identificaram que a maioria dos professores entrevistados considera positiva a inserção da história e filosofia da ciência nos cursos e afirmam utilizar em suas aulas. No entanto, o perfil de formação dos docentes indica que uma expressiva maioria não possui formação na área e que há um predomínio da contextualização histórica e internalista da física em detrimento das discussões epistemológicas.

Nicolodelli (2011), com o objetivo de diagnosticar a presença e o conteúdo de disciplinas específicas de caráter histórico e/ou epistemológico em cursos de formação de Licenciatura e Bacharelado em Física em IES brasileiras, analisou os planos de ensino, ementas e PPC de 19 universidades federais (25,7\% do total de instituições) com oferta de cursos de formação em física à época. Em sua análise, utilizando a classificação Staub e Peduzzi (2004), evidenciou que grande parte das instituições promovem a inclusão de disciplinas que abordam história da ciência e da física sem vínculos com a filosofia e epistemologia da ciência e que há uma valorização maior do tema na licenciatura em relação ao bacharelado. Uma alternativa para tentar superar este problema defendido por Nicolodelli (2011) é de que discussões em torno da história da física sejam promovidas em disciplinas de física básicas e específicas, oferecidas para quaisquer habilitações.

Londero (2015), ao investigar a oferta e inserção do conteúdo de história e filosofia da ciência na estrutura curricular de 23 instituições de Ensino Superior do estado de Minas Gerais, identifica 24 cursos que apresentavam disciplinas com discussão sobre a temática, totalizando 31 disciplinas. Estas disciplinas apresentavam uma diversidade de objetivos e abordagens, tais como: introdução do pensamento científico, sobre as posições e obstáculos da ciência moderna; análise da história, da filosofia e da epistemologia do desenvolvimento dos conceitos da física em diferentes tempos históricos; discussão do papel social e cultural da física contemporânea; análise das diversas concepções da ciência através dos tempos. 
Ao que parece, mesmo com a inserção de disciplinas com conteúdo histórico, filosófico, epistemológico, sociológico das ciências nos currículos dos cursos de graduação em física, o debate da natureza da ciência a partir de uma perspectiva histórica possui um enfoque internalista (ROSA; MARTINS, 2007; PEREIRA; MARTINS, 2011; NICOLODELLI, 2011). Ademais muitas vezes desarticulado do debate filosófico e epistemológico, ou ainda, o debate filosófico surge sem conexão com aspectos históricos (NICOLODELLI, 2011; LONDERO, 2015). Maior desarticulação ainda existe entre disciplinas de caráter histórico, filosófico, epistemológico com o debate metodológico no ensino das ciências, fundamental para a formação de professores na área. Este ponto é particularmente importante de ser destacado, tendo em vista que os saberes necessários para esta articulação estão para além dos conteúdos emergentes da tradição universitária dos saberes disciplinares (TARDIF, 2014b).

Depreende-se que as preocupações e encaminhamentos sinalizados convergem para o objetivo de melhor qualificar a formação docente sobre natureza da ciência. A nosso ver, esta qualificação inclui um mapeamento sistematizado das disciplinas com discussões sobre natureza da ciência em cursos de LF no Brasil. Nos últimos anos, o aumento do número de cursos de formação de professores da área de ciências da natureza no contexto nacional também justifica uma análise abrangente das matrizes curriculares destes cursos. Ainda que o conjunto de cursos de formação de professores, em suas mais diversas especificidades, esteja/seja regido e orientado pelas mesmas legislações e diretrizes, há uma multiplicidade de outros elementos, objetivos e subjetivos, que influenciam e incidem sobre a maneira como os cursos se originam, se organizam e se desenvolvem. Sejam elementos pedagógicos, culturais, históricos, políticos ou sociais, originários das demandas locais ou globais, de curto, médio e longo prazo, desde a constituição dos currículos à definição dos perfis dos profissionais e professores que atuam nos cursos. As configurações e cenários que se constroem para qualquer debate dentro dos cursos, portanto, são complexas e diversas. Acreditamos que é em uma complexidade e diversidade de cenários que também se constrói o debate sobre a temática da natureza da ciência nos cursos de LF no Brasil. Neste sentido, a pesquisa foi orientada pelas seguintes questões de pesquisa: Qual a dimensão da inserção de reflexões sobre a natureza da ciência na formação de professores de física em cursos de graduação de instituições públicas de Ensino Superior? Quais os aspectos da natureza da ciência são privilegiados na formação inicial de professores de física nestas instituições?

\section{Perspectivas teórico-metodológicas do debate sobre Natureza da Ciência na Educação Científica}

No debate da natureza da ciência é possível identificar uma diversidade de abordagens teórico-metodológicas que orientam os estudos, reflexões e investigações desenvolvidas, algumas mais clássicas, tradicionalmente utilizadas na inserção deste debate nas aulas de ciências, e outras perspectivas mais renovadas, que apresentam críticas às 
anteriores e vêm ganhando espaço nas aulas de ciências e na formação de professores na última década.

Dentre as perspectivas clássicas estão as abordagens teórico-metodológicas que propõem uma visão consensual sobre a natureza da ciência, cujas ideias centrais podem ser identificadas nos trabalhos de Abd-El-Khalick (2012a, 2012b), Driver et al. (1996), Lederman (1992, 2006), Lederman, Bartos e Lederman (2014), Lederman e Abd-El-Khalick (1998), Lederman et al. (2002), McComas (2008), McComas e Olson (1998), McComas, Almazroa e Clough (1998), McComas, Clough e Almazroa (1998), Osborne et al. (2003), Ryder (2001, 2002), Gil-Pérez et al. (2001). Nesta perspectiva consensual, a natureza da ciência é definida como "um domínio híbrido que combina aspectos de vários estudos sociais da ciência (...) numa rica descrição da ciência; como funciona, como os cientistas operam como um grupo social e como a própria sociedade dirige e reage aos empreendimentos científicos" (McCOMAS, 2008, p. 249-250).

As propostas pedagógicas para seu ensino se baseiam em afirmações sobre a natureza da ciência, como a proposta por Lederman et al. (2002) em que sistematizam princípios sobre natureza da ciência e algumas generalizações a serem interpretadas no contexto da educação escolar, ainda que possam existir diferentes níveis de profundidade e complexidade dependendo da situação. Estas generalizações estão em torno de afirmações sobre: provisoriedade do conhecimento científico; base empírica do conhecimento científico; carga teórica do conhecimento científico; conhecimento científico como parcialmente produto da inferência, imaginação e criatividade humana; conhecimento científico como social e culturalmente incorporado; importância da distinção entre observação e inferência; a falta de um método de reciprocidade universal para fazer ciência; e, as funções e relações entre teorias e leis científicas.

Segundo os críticos da visão consensual, não parece ser possível estabelecer um acordo geral sobre a natureza da ciência no contexto da educação científica, pois "há diferentes rotas, terminologias, pontos de partida e conclusões" (MARTINS, 2015, p. 703). Entre as fragilidades, alguns problemas se destacam, como por exemplo: crítica ao estabelecimento de afirmações declarativas sobre ciência (CLOUGH, 2006, 2007; ALLCHIN, 2011; MARTINS, 2015) que sugerem um aspecto dogmático para a abordagem e aprendizagem sobre ciências, desconsideração das particularidades das diversas áreas das ciências (IRZIK; NOLA, 2011), e pouco refinamento histórico e filosófico dos elementos da natureza da ciência (MATTHEWS, 2012; Martins, 2015).

Dentre as perspectivas renovadas sobre a natureza da ciência estão as abordagens teórico-metodológicas que apresentam pressupostos emergentes a partir de marcos renovados e potentes para a didática das ciências, e buscam superar as principais críticas, tanto de caráter epistemológico quanto educacional, à perspectiva clássica da visão consensual (RODRÍGUEZ; ADÚRIZ-BRAVO, 2017; MARTINS, 2015). Entre os argumentos estão a busca por abordar aspectos da natureza da ciência como questões em vez de princípios 
(CLOUGH, 2006, 2007; MARTINS, 2015), explorar estudos de caso históricos contextualmente ricos (ALLCHIN, 2011; FORATO; BAGDONAS; TESTONI, 2017), estudo de práticas científicas a partir de diferentes perspectivas teóricas (DUSCHL; GRANDY, 2013; GARCÍA-MARTÍNEZ; IZQUIERDO-AYMERICH, 2014; MOURA et al., 2017), entre outros. Algumas destas perspectivas têm se destacado e, inclusive, desempenhado um papel central para o desenvolvimento de investigações empíricas atuais sobre a temática. Entre elas estão as seguintes perspectivas: a abordagem das Características da Ciência (Features of Science) proposta por Matthews (2012); a abordagem da Natureza da Ciência 'Completa' (Nature of 'Whole' Science) proposta por Allchin (2011); a abordagem de Semelhança Familiar (Family Resemblance Approach) proposta por Irzik e Nola (2011); a abordagem de Campos Teóricos Estruturantes proposta por Adúriz-Bravo (2005); a abordagem da natureza da ciência por meio de questões propostas por Martins (2015).

Por exemplo, Matthews (2012) propõe uma mudança terminológica da visão consensual de natureza da ciência para características da ciência. Este autor sugere a utilização de questões filosóficas para o tratamento de tais aspectos, e acrescenta às listas de Lederman et al. (2002) itens que considera como características da ciência: experimentação, idealização, modelos, valores e questões sócio científicas, matematização, tecnologia, explicação, visão de mundo e religião, escolha teórica e racionalidade, feminismo, realismo e construtivismo. Já Allchin (2011) busca promover uma discussão sobre como efetivamente avaliar o conhecimento prático e culturalmente funcional da natureza da ciência. Este autor propõe uma série de dimensões a serem utilizadas como instrumento de avaliação de casos históricos ou notícias contemporâneas da ciência, que sejam contextualmente ricas, a fim de promover uma análise funcional ou interpretativa da natureza da ciência, em substituição à abordagem em torno de afirmações declarativas. Entre as dimensões propostas pelo autor estão: observação e raciocínio, métodos de investigação, história e criatividade, contexto humano, cultura, interações sociais entre cientistas, processos cognitivos, economia/financiamento, instrumentação e práticas experimentais, comunicação e transmissão de conhecimentos.

Irzik e Nola (2011) propõem uma abordagem a partir de aspectos gerais e estruturais. Entre os aspectos que contribuem de forma importante para a caracterização das disciplinas científicas, definem como essencial quatro classes: atividades, objetivos e valores, metodologias e regras metodológicas e produtos. Nesta abordagem, cada ciência individual será formada por algum subconjunto de elementos pertencentes a cada uma das quatro categorias, que pode ser diferente de um outro subconjunto que caracteriza outra ciência individual. Por fim, cada uma das quatro categorias é aberta a novas características que comporão os subconjuntos, assim como outras categorias podem surgir e ser acrescentadas à medida que a ciência se desenvolve.

Adúriz-Bravo (2005) propõe uma abordagem a partir de uma perspectiva metateórica com base em estágios constituídos por uma periodização epistemológica acadêmica e 
em vertentes da natureza da ciência definidas com base em preocupações filosóficas da ciência. Conforme proposto, os estágios epistemológicos contemplam: o positivismo lógico (1920-1965) que sustenta uma reconstrução racionalista e realista rigorosa da ciência tanto como processo quanto como produto; o racionalismo crítico e nova filosofia da ciência (19351980); o pós-modernismo e visões contemporâneas (1970-atual), que combinam construções filosóficas 'emergentes' com elementos de outras metaciências (sociologia da ciência, ciência cognitiva, estudos da ciência). Enquanto as vertentes epistemológicas consistem em: Correspondência e Racionalidade, Representação e Linguagens, Intervenção e Metodologias, Contexto e Valores, Evolução e Julgamento, Demarcação e Estrutura, Normatividade e Recursão. Nesta matriz estágios x vertentes, é possível mapear diferentes modelos teóricos sobre ciência, bem como avaliar sua pertinência na formação de professores de ciências, no sentido de permitir opções mais claras ao selecionar elementos a serem ensinados sobre a natureza da ciência.

Martins (2015) apresenta uma proposta com base em 'temas e questões' para a abordagem da temática da natureza da ciência no currículo, a partir de dois eixos principais: eixo sociológico e histórico (contemplando temas como papel do indivíduo e da comunidade científica; intersubjetividade; questões morais, éticas e políticas; influências históricas e sociais; ciência como parte da cultura; comunicação do conhecimento) e eixo epistemológico (contemplando temas como origem do conhecimento; métodos, práticas, procedimentos e processos da ciência; conteúdo/natureza do conhecimento produzido). Nesta abordagem, o autor sugere uma interrelação entre os dois eixos e uma mudança de forma e de conteúdo em relação às listas da visão consensual, com a proposição de questões e temas de natureza sociológica, histórica e epistemológica. Nesse sentido, parece bastante importante que estas discussões, das abordagens clássicas a renovadas, estejam presentes nas discussões desenvolvidas na formação de professores sobre a natureza da ciência.

\section{Metodologia de investigação}

\section{III.1 Amostra}

Com a finalidade de esboçar cenários abrangentes das configurações atuais dos cursos de Licenciatura em Física (LF) em torno da oferta de disciplinas com discussões sobre a natureza da ciência nas instituições de Ensino Superior (IES) públicas, desenvolvemos uma pesquisa documental de abordagem qualitativa (TOZONI-REIS, 2010), de caráter exploratório e explicativo (GIL, 2007), apoiados por uma análise quantitativa que auxiliou na caracterização mais ampla deste contexto.

Utilizamos como fonte de informação da pesquisa os Projetos Pedagógicos de Curso (PPC) e Matrizes Curriculares (MC) de cursos de LF de IES públicas do Brasil, portanto documentos e fontes primárias de informação, sem tratamento analítico. A identificação, 
localização e obtenção do material para análise ocorreu na base de credenciamento do MEC ${ }^{2}$, por constituir a base de dados oficial do Instituto Nacional de Estudos e Pesquisas Educacionais Anísio Teixeira com informações relativas às IES. Na sequência procedemos à busca dos PPC e MC nas páginas eletrônicas institucionais e, na falta desses, individualmente por e-mail e/ou telefone de contato dos departamentos, coordenações e secretarias dos cursos.

Esta etapa da investigação, de pesquisa documental, foi realizada entre os períodos de outubro de 2015 e outubro de 2016 e abrangeu uma amostra de 145 cursos, de 90 instituições, de um universo de 186 cursos de 111 instituições; isto é, aproximadamente 78\% dos cursos oferecidos, de cerca de $81 \%$ das IES públicas que ofertam regularmente o curso de LF na modalidade presencial, abrangendo instituições de todas as regiões e estados brasileiros ${ }^{3}$.

Restringimos esta investigação apenas aos cursos presenciais e de instituições públicas, eliminando-se cursos na modalidade a distância, cursos de instituições privadas, ou ainda cursos de Licenciatura Interdisciplinares, tais como Licenciatura em Ciências e Licenciatura em Ciências Exatas que também oferecem a habilitação em Física. Esta restrição ocorreu porque:

- Cursos de LF à distância e de algumas IES privadas nem sempre tem oferta regular, podendo ocorrer por demanda da comunidade ou por editais não periódicos de incentivo à formação de professores em determinadas regiões do país. Ainda, com frequência, a cada nova oferta, os cursos e seus currículos são reformulados, o que dificulta uma análise mais consistente em torno de suas configurações.

- Com relação aos cursos ofertados por IES privadas, tivemos acesso a documentos curriculares de apenas seis cursos de LF de um universo de 30, pouco representativa (20\%), especialmente se comparado à amostra reunida de cursos de LF ofertados por IES públicas $(78 \%)$.

- Com relação aos cursos interdisciplinares, seus PPC são bastante abrangentes e diversificados.

É importante esclarecer que compreendemos que o PPC e a MC não representam necessariamente a realidade acadêmico-escolar, podendo ser apenas um documento situado entre a declaração de princípios gerais e sua tradução operacional, entre a teoria educativa e a prática pedagógica, entre o planejamento e a ação, entre o que se prescreve e o que acontece de fato na sala de aula (COLL, 1986). Há sim uma distância entre quem escreve e quem implementa o PPC. No entanto, apesar das limitações, a análise destes documentos nos auxilia a compreender uma das várias facetas deste campo de pesquisa no que se refere à

\footnotetext{
${ }^{2}$ O sistema e-MEC opera a tramitação eletrônica de processos de regulamentação dos cursos superiores, como credenciamento, recredenciamento, autorização de funcionamento, reconhecimento e renovação de reconhecimento dos cursos, disponível em $<$ http://emec.mec.gov.br/>.

${ }^{3}$ Neste artigo foram adicionadas apenas parte das análises e informações sobre os cursos de graduação que compuseram a amostra desta pesquisa. Para mais informações e análises, consultar Ferreira (2018).
} 
formalização sobre o que se pretende desenvolver no contexto propositivo da LF, seja com base nas diretrizes e legislações para a formação de professores e para a formação de Físicos, ou então influenciados pela tradição de pesquisa da área da educação científica e do ensino de física.

\section{III.2 Tratamento dos dados e instrumento de análise}

Com a finalidade de esboçar cenários abrangentes das configurações atuais dos cursos de Licenciatura em Física (LF) em torno da oferta de disciplinas com discussões sobre a natureza da ciência nas instituições de Ensino Superior (IES) públicas, desenvolvemos uma pesquisa documental de abordagem qualitativa (TOZONI-REIS, 2010), de caráter exploratório e explicativo (GIL, 2007), apoiados por uma análise quantitativa que auxiliou na caracterização mais ampla deste contexto.

Os dados obtidos foram analisados por meio da Análise de Conteúdo (BARDIN, 2011), levando em conta, nas fases de pré-análise e de exploração do material, os critérios de representatividade, homogeneidade e pertinência. Representatividade por compreendermos que a amostra obtida, de aproximadamente $78 \%$ de documentos do universo de dados, sendo que há documentos de instituições ( $81 \%$ das instituições do país) homogeneamente distribuídos geograficamente (de todas as regiões e unidades federativas do Brasil) e de todas as categorias administrativas (municipal, estadual e federal). Homogeneidade e pertinência pelo fato de esses documentos constituírem fontes de informação adequadas ao objetivo que pretendemos, que consiste em mapear a oferta de disciplinas com discussões sobre a temática de interesse.

$\mathrm{Na}$ fase de tratamento dos resultados, inferências e interpretação, as unidades de registros (nível dos recortes) consistiram em palavras-chave que representassem a temática de interesse - natureza da ciência - e que nos permitisse, por meio da análise temática, encontrar e evidenciar núcleos de sentido e significação que a constituíam. Então, apesar de definirmos como unidades de registro um conjunto de palavras-chave, nossa análise se pretendeu temática e se deu em torno do contexto próximo a estas unidades. Buscamos, portanto, nos PPC e MC dos cursos de LF, ainda da fase de pré-análise, enunciações e nomeações (e suas variações) para disciplinas que tratavam em suas ementas de discussões sobre natureza da ciência, a partir das seguintes unidades de registro que foram definidas a priori. Foram elas: natureza da(s) (abordagem/análise/relação entre/da) ciência(s)/científica; pensamento científico; atividade/prática/trabalho científico(a); história da(s) (abordagem/análise/relação histórica $\mathrm{da}(\mathrm{s})$ ) física/ciência(s); filosofia da(s) (abordagem/análise/relação filosófica da(s)) física/ ciência(s); epistemologia da(s) (abordagem/análise/relação epistemológica da(s)) física/ciência(s); evolução (das ideias) da(s) física/ciência(s); evolução do(s) conhecimento(s) físico(s)/científico(s).

A decisão por buscar estas palavras-chave nas ementas/ementários, e não em outras partes das documentações dos cursos, tais como planos de ensino ou planos/programas de 
curso, se deveu ao fato de que, entre todos esses, as ementas são os elementos textuais mais frequentes na constituição das disciplinas, que apresentam informações importantes como nome, carga horária, modalidade e regularidade de oferta, e conhecimentos/conteúdos curriculares obrigatórios. Além do mais, em nosso entendimento, a presença destas palavraschave no título ou no texto da ementa poderia evidenciar a presença de discussões explícitas sobre aspectos da atividade científica e da natureza da ciência nestas disciplinas. Outros termos como 'questões controversas sobre ciência', 'situações sócio científicas', 'ciência, tecnologia e sociedade', 'investigação científica', presentes em investigações e estudos da literatura da área (GARCÍA-CARMONA; VÁZQUEZ-ALONSO, MANASSERO-MAS, 2011, 2012), sempre que se referiam ao contexto de discussões que envolvem alguma compreensão da natureza da ciência foram incorporados dentro das unidades de registro.

É importante ressaltar que disciplinas de história da ciência ou história da física não necessariamente apresentam discussões sobre a natureza da ciência, no entanto, percebemos que em grande parte das vezes discussões sobre natureza da ciência acontecem em disciplinas com a denominação 'história'. Em estudo sobre as tendências curriculares dos cursos de física dos anos noventa, Carvalho e Vannucchi (1995) identificaram que as propostas de inovação curricular no ensino de física que enfatizam a história e filosofia da ciência englobam discussões sobre "a epistemologia da ciência, sua natureza, seu caráter de construção permanente, ou na sua dimensão cultural, conhecimento socialmente constituído" (CARVALHO; VANNUCCHI, 1995, p. X).

Conforme proposto por Bardin (2011) para a Análise de Conteúdo, ainda na fase de tratamento dos resultados, inferências e interpretação, em nível de enumeração, recorremos às regras com relação à presença, frequência e coocorrência de determinadas categorias dentro das ementas das disciplinas. Enquanto, em nível de classificação e agregação, utilizamos como critério a classificação semântica, isto é, definindo categorias temáticas que fossem condizentes com as características associadas a uma boa categorização.

Assim, com auxílio da Análise de Conteúdo, selecionamos e analisamos 390 ementas de disciplinas utilizando como critério de classificação o semântico. Para tanto definimos categorias temáticas, com base na literatura da área sobre o debate da natureza da ciência na educação científica, que julgamos condizentes com as características associadas a uma boa categorização, conforme proposto por Bardin (2011). A análise realizada leva em consideração, portanto, as tendências em pesquisa e perspectivas teórico-metodológicas do debate sobre natureza da ciência na educação científica.

A pré-análise, exploração do material e, especialmente, o tratamento dos resultados no que diz respeito à categorização e análise das ementas foi realizada utilizando o software de análise de dados qualitativos denominado Atlas.ti - Qualitative Data Analysis. Esse software comporta a análise de documentos diversos (textos, áudio, vídeo, imagens) é indicado para o tratamento de grandes volumes de dados e com caráter longitudinal, 
possibilitando a sistematização e análise de fenômenos complexos e intrinsecamente relacionados.

\section{Dados e análise de cursos de Licenciatura em Física em disciplinas com conteúdo da Natureza da Ciência}

No conjunto dos cursos analisados, cerca de 58\% são ofertados no período noturno, $32 \%$ no período integral ou diurno (dois períodos ou mais), $9 \%$ no período vespertino e $1 \%$ no período matutino. Com relação ao ano de implementação da última versão do PPC do curso, cerca de 38\% dos documentos aos quais tivemos acesso são versões de 2010 ou anteriores, $15 \%$ de 2011 e 2012, 19\% de 2013 e 2014, 14\% de 2015 e 2016, e 14\% dos documentos não mencionam o ano de implementação da última versão do PPC.

Nestes cursos, com auxílio da Análise de Conteúdo (BARDIN, 2011), encontramos 390 disciplinas com discussões referentes à natureza da ciência, sendo que 303 são disciplinas de caráter obrigatório ( $77,7 \%$ do total) e 87 de caráter optativo ou eletivo (22,3\% do total). Estas 390 disciplinas possuem uma carga horária individual média de 54 horas diluídas em uma carga horária média dos cursos de cerca de 3121 horas. Esta carga horária é compatível com a exigência mínima para integralização do currículo, isto é, para o cumprimento de disciplinas obrigatórias - entre as quais disciplinas gerais e específicas, estágios curriculares e práticas como componente curricular - disciplinas optativas e eletivas e atividades formativas e complementares. Portanto, no cenário atual dos cursos de LF, modalidade presencial, oferecidos pelas IES públicas do país, apenas 4,65\% da carga horária dos cursos de LF de IES públicas no Brasil (razão entre a carga horária total de disciplinas com discussões sobre a natureza da ciência e a carga horária total dos cursos de LF analisados) se referem a disciplinas que, entre outros assuntos propostos em suas ementas, também tratam de discussões sobre a natureza da ciência. Outro ponto a ser mencionado é de que a oferta destas disciplinas ocorre com maior frequência nas fases finais do curso: $17,1 \%$ são ofertadas nas $1^{\text {a }}$ e $2^{\mathrm{a}}$ fases, $13,9 \%$ nas $3^{\mathrm{a}}$ e $4^{\mathrm{a}}$ fases, $24,0 \%$ nas $5^{\mathrm{a}}$ e $6^{\mathrm{a}}$ fases, $37,3 \%$ da $7^{\mathrm{a}}$ fase em diante. Em relação a 7,7\% das disciplinas, não encontramos menção as fases que são ofertadas

Ainda na primeira etapa da Análise de Conteúdo, a pré-análise caracterizada pela leitura flutuante do material a ser submetido à análise sistematizada (BARDIN, 2011), foi possível identificar três grupos ou conjuntos de disciplinas que foram classificadas a partir da noção de saberes docentes, conforme proposto por Tardif (2014a, 2014b). As ementas foram classificadas em cada um destes grupos por apresentarem prioritariamente conteúdos referentes a cada um dos saberes disciplinares ou dos saberes pedagógicos, ainda que também mencionassem em suas ementas outros saberes para além dos identificados.

O primeiro grupo é denominado de Saberes Disciplinares de História, Filosofia, Epistemologia e Sociologia da(s) Ciência(s) e da Física (SDHFESC/F). Os conteúdos destas disciplinas referem-se aos saberes sociais emergentes da tradição dos estudos em história, filosofia, epistemologia e sociologia da(s) ciência(s) selecionados e presentes na instrução 
universitária. Este grupo é composto por 284 disciplinas (72,8\% das 390 disciplinas), sendo 208 obrigatórias e 76 optativas/eletivas, com discussões exclusivas à temática da natureza da ciência. As disciplinas que constituem este primeiro grupo foram identificadas pela presença de trechos com referência à "história, filosofia, epistemologia, evolução da(s) ciência(s) e da física", nos seus títulos e ementas. A carga horária de disciplinas classificadas como SDHFESC/F é de 3,39\% da carga horária média dos cursos de LF analisados.

O segundo grupo é denominado de Saberes Pedagógicos (SP). Os conteúdos destas disciplinas referem-se aos saberes de formação profissional geradores e provenientes de reflexões sobre a prática educativa com a intenção de serem incorporados à atividade docente. Este grupo é composto por 79 disciplinas (20,3\% das 390 disciplinas), sendo 71 obrigatórias e 8 optativas/eletivas, com discussões na área de ensino de ciências e de física que, em grande parte, abordam aspectos didático-metodológicos da área de ensino. As disciplinas que constituem este segundo grupo foram identificadas pela presença de trechos com referência ao "uso da história/filosofia/epistemologia $\mathrm{da}(\mathrm{s})$ ciência(s)/da física no ensino de ciência(s)/física", nas suas ementas, e nomeadas como "Prática de Ensino de Ciências/Física", "Metodologia de Ensino de Ciências/Física", "Instrumentação para o Ensino de Física". A carga horária de disciplinas classificadas como SP é de $0,94 \%$ da carga horária média dos cursos de LF analisados.

O terceiro grupo é denominado de Saberes Disciplinares de Física (SDF). Os conteúdos destas disciplinas referem-se aos saberes sociais emergentes da tradição dos estudos da física selecionados e presentes na instrução universitária. Este grupo é composto por 27 disciplinas (6,9\% das 390 disciplinas), sendo 24 obrigatórias e 3 optativas/eletivas, que tratam especificamente de conteúdos de física e ressaltam em suas ementas discussões em torno de aspectos históricos, filosóficos e/ou epistemológicos do conhecimento Físico em questão. As disciplinas que constituem este terceiro grupo foram identificadas pela presença de trechos com referências a conceitos físicos em seus nomes e ementas. A carga horária de disciplinas classificadas como SDF é de $0,32 \%$ da carga horária média dos cursos de LF analisados.

Os dados referentes ao caráter de oferta de disciplinas (obrigatórias ou optativas) e à carga horária nos permitem afirmar que há uma preocupação, ainda que em pequena proporção, em atender as demandas da legislação sobre formação de professores com relação às discussões sobre a natureza da ciência. De uma maneira geral, 4,65\% da carga horária dos cursos são destinadas a discussões sobre o tema, mas parte das disciplinas não trata exclusivamente este tipo de discussão (SP e SDF) e aborda uma gama de conteúdos, também pertinentes à formação dos licenciandos, mas com características diversas. Além disso, como parte das disciplinas pertencentes aos grupos é de caráter optativo/eletivo e desempenham função de complementaridade à formação principal, não podemos afirmar que o debate da natureza da ciência seja contemplado na formação profissional dos licenciandos de algumas instituições investigadas. 
$\mathrm{Na}$ LF, os estudantes fazem suas escolhas a partir de uma lista variada, que apresentam inclusive algumas opções sobre temas específicos e atuais da física, de grande interesse dos licenciandos. Nesse sentido, considerando apenas as disciplinas obrigatórias, aquelas classificadas como SDHFESC/F, que apresentam discussões exclusivas ao tema da natureza da ciência, ocupam apenas $2,48 \%$ da carga horária dos cursos de LF, enquanto que para aquelas classificadas como SP e SDF, que além de outros conteúdos abrangem a natureza da ciência, a carga horária reduz para apenas 1,13\% nos dois grupos.

Estes dados nos levam a duas considerações importantes. Primeiro, há pouco espaço e tempo destinado a discussões exclusivas à temática da natureza da ciência. Segundo, menor dedicação ainda para integrar esta temática a outras disciplinas e conteúdos como os da área de ensino e da física, que buscamos identificar nos conteúdos das disciplinas classificadas como sendo referentes aos SP e SDF, respectivamente. Ainda que a dedicação de carga horária não seja tão expressiva, é importante refletir sobre como tornar o debate sobre a natureza da ciência mais efetivo, incorporando-a inclusive ao debate metodológico e para a aprendizagem da própria física (MARTINS, 2007; PEREIRA; MARTINS, 2011).

Para além da classificação das disciplinas em cada um dos tipos de saberes apresentados até aqui pela identificação das informações sobre carga horária, periodização, caráter obrigatório ou optativo, bem como categorização e análise de suas ementas em relação ao conteúdo que será apresentado na próxima seção, percebemos ser importante identificar quais cursos e instituições concentram as ofertas de disciplinas. Nesse sentido, identificamos os cursos de LF de IES públicas no Brasil que oferecem disciplinas sobre a temática da natureza da ciência junto aos conteúdos associados aos SP e aos SDF.

Dos 145 cursos de LF de IES públicas do Brasil, grande parte, 65,5\% do total (95 cursos), apresenta em suas estruturas curriculares apenas disciplinas que abordam a temática da natureza da ciência classificadas como SDHFESC/F (sendo 143 delas obrigatórias e 42 optativas/eletivas), totalizando 185 disciplinas (que representam 47,4\% do total de disciplinas). Outra parcela dos cursos, $22,8 \%$ do total (33 cursos), apresenta em suas estruturas curriculares disciplinas, que abordam a temática da natureza da ciência, classificadas como SDHFESC/F (68 disciplinas, sendo 44 obrigatórias e 24 optativas/eletivas, que representam 17,4\% do total de disciplinas) e como SP (67 disciplinas, sendo 60 obrigatórias e 7 optativas/eletivas, que representam 17,2\% do total de disciplinas), totalizando 135 disciplinas. Uma terceira parcela dos cursos, 6,9\% do total (10 cursos), apresenta em suas estruturas curriculares disciplinas, que abordam a temática da natureza da ciência, classificadas como SDHFESC/F (22 disciplinas, sendo 13 obrigatórias e 9 optativas/eletivas, que representam 5,6\% do total de disciplinas) e como SDF (18 disciplinas, sendo 17 obrigatórias e 1 optativas/eletivas, que representam $4,6 \%$ do total de disciplinas), totalizando 40 disciplinas (que representam $10,2 \%$ do total de disciplinas). Uma quarta parcela dos cursos, 3,45\% do total ( 5 cursos), apresenta em suas estruturas curriculares disciplinas, que abordam a temática da natureza da ciência, classificadas como SDHFESC/F (9 disciplinas, 
sendo 8 obrigatórias e 1 optativas/eletivas, que representam $2,3 \%$ do total de disciplinas), como SP (11 disciplinas, sendo todas obrigatórias, que representam 2,8\% do total de disciplinas) e também como SDF ( 8 disciplinas, sendo 6 obrigatórias e 2 optativas/eletivas, que representam $2,1 \%$ do total de disciplinas), totalizando 28 disciplinas (que representa 7,2\% do total de disciplinas). Somente um curso $(0,7 \%)$ apresenta em sua estrutura curricular apenas uma disciplina, que aborda a temática da natureza da ciência, classificada como SP (que representa $0,3 \%$ do total de disciplinas) e outro curso $(0,7 \%)$ apenas uma disciplina como SDF (que representa $0,3 \%$ do total de disciplinas). Nenhum curso oferta apenas disciplinas, que abordam a temática da natureza da ciência, classificadas como SP e SDF.

Em suma, grande parte dos cursos apresenta em suas MC apenas disciplinas, que abordam a temática da natureza da ciência, referentes aos SDHFESC/F. Uma parcela um pouco menor dos cursos apresenta em suas MC tanto disciplinas que abordam a temática da natureza da ciência, referentes aos SDHFESC/F, quanto aos SP, isto é, que propõem a discussão da temática da natureza da ciência também associado ao debate dos aspectos didático-metodológicos da área de ensino de ciências/física. Uma parte menor dos cursos apresenta em suas MC tanto disciplinas, que abordam a temática da natureza da ciência, referentes aos SDHFESC/F, quanto aos SDF, isto é, que propõem alguma intersecção da discussão da temática da natureza da ciência também associado ao estudo e compreensão conceitual do conhecimento da física. Por fim, uma parte ainda menor apresenta em suas MC disciplinas, que abordam a temática da natureza da ciência, referentes aos SDHFESC/F, SP e SDF. Esta sistematização está representada na Fig. 1.

Nas disciplinas do tipo SP se constata uma preocupação mais efetiva com a didatização do conhecimento científico - a discussão do quê, como, para quê e para quem ensinar ciências/física, sobre a transposição didática, sobre procedimentos e estratégias didático-metodológicas, das perspectivas ditas tradicionais às inovadoras. Assim, mesmo que a quantidade de cursos (segunda e quarta barras cinza na Fig. 2) que possuem disciplinas classificadas como SP (barras azuis na Fig. 2) seja representativa $(26,2 \%=22,8 \%$ dos cursos $+3,4 \%$ dos cursos), ainda nos parece que uma parcela pequena e de carga horária reduzida é dedicada às disciplinas que trabalham a didatização de conteúdos sobre a natureza da ciência nos cursos de LF (representados pelos elementos internos ao círculo azul inferior esquerdo da Fig. 1).

No mesmo sentido, os dados evidenciam que uma parcela muito pequena de cursos $(10,3 \%=6,9 \%$ dos cursos $+3,4 \%$ dos cursos representados pela terceira e quarta barras cinza na Fig. 2) apresentam o debate da natureza da ciência tanto em disciplinas classificadas como sendo do tipo SDF (barras verde da Fig. 2) como nas do tipo SDHFESC/F (barras laranja na Fig. 2). 


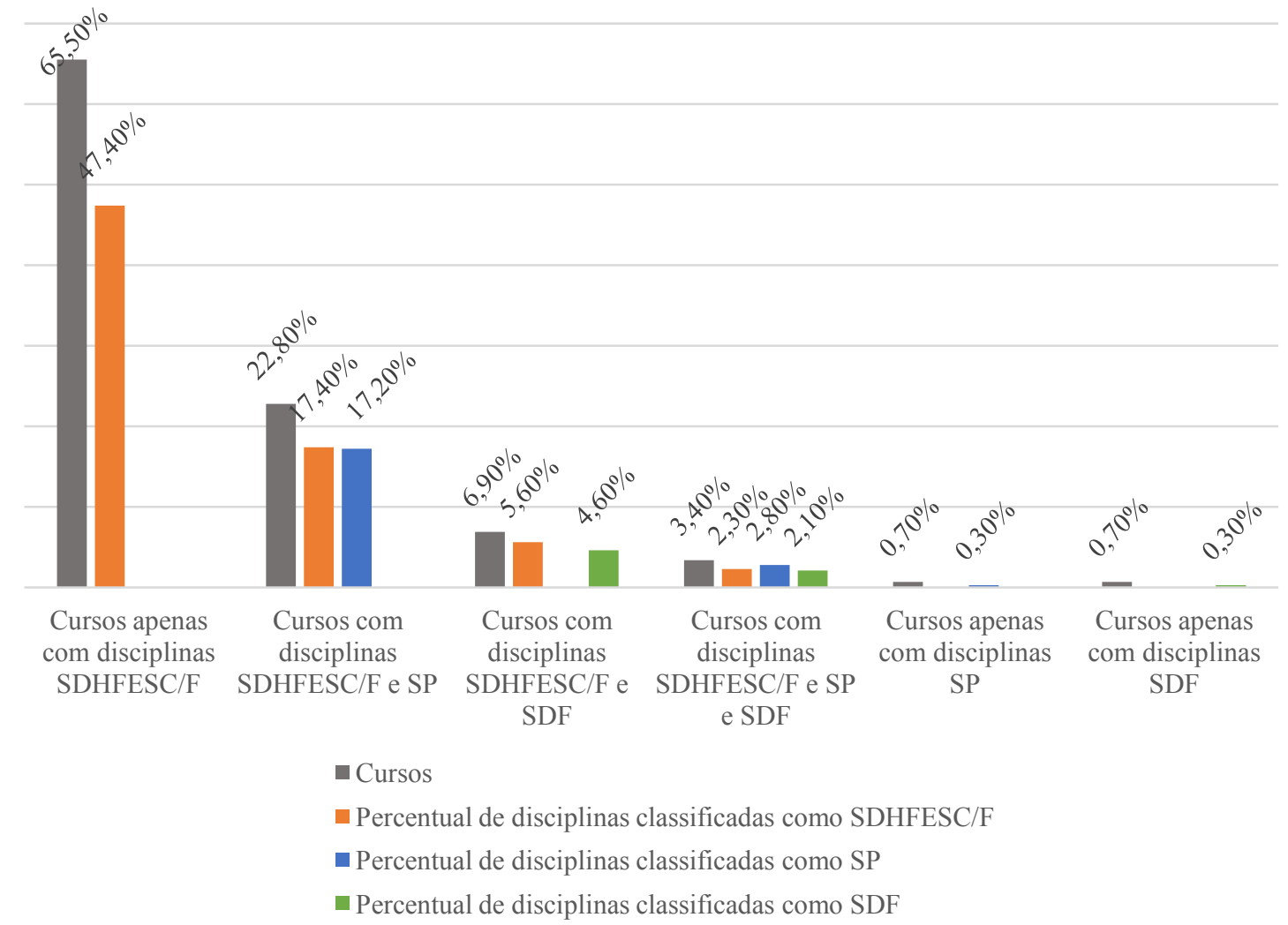

Fig. 1 - Distribuição de cursos (barras cinza) que apresentam em suas matrizes curriculares disciplinas referentes aos SDHFESC/F, SP e SDF nos cursos de LF de IES públicas no Brasil. Fonte: Ferreira (2018).

A baixa frequência de disciplinas classificadas como SP e como SDF junto a disciplinas classificadas como SDHFESC/F parecem evidenciar uma fraca presença deste tipo de discussão e, talvez, seja um indicador de que a articulação entre temas da natureza da ciência e temas de ensino, bem como temas da natureza da ciência e conteúdos de física aconteçam ainda de maneira muito tímida nos cursos de LF nas IES públicas no Brasil. Se, de fato, o debate e a articulação entre os SDHFESC/F e os SP são ausentes ou ainda incipientes na formação de professores de física, há chances de que a formação destes professores seja permeada pela construção de uma concepção ingênua sobre a natureza da ciência, crítica que vem sendo amplamente feita pesquisadores da área da educação em ciências e professores de ciências.

Esta análise, amparada pela categorização das ementas das disciplinas reunidas que será apresentada na seção seguinte, nos forneceu indícios para a caracterização dos momentos em que discussões sobre natureza da ciência surgem nos cursos de LF. Pelos dados até aqui expostos, parece aceitável advogar por uma quantidade mais expressiva e diversificada de disciplinas com discussões em torno da natureza da ciência, dentro da diversidade de perspectivas e abordagens possíveis, como formação obrigatória para os futuros professores. 
Nesse sentido aprofundamos a análise para evidenciar o que se pretende ensinar sobre a natureza da ciência nas disciplinas dos grupos Saberes Disciplinares de História, Filosofia, Epistemologia e Sociologia da(s) Ciência(s) e da Física, Saberes Pedagógicos e Saberes Disciplinares de Física.

\section{Categorização e análise das ementas}

\section{V.1 Categorização das ementas}

Embasados pelos referenciais que discutem a importância do debate da natureza da ciência na educação científica, construímos seis categorias que partiram das unidades de registro definidas a priori, subdivididas em subcategorias definidas a posteriori. Cada uma das ementas foi fragmentada em extratos/trechos que se referiam às categorias e subcategorias, analisadas e categorizadas em apenas uma categoria/subcategoria, respeitando o princípio da exclusão mútua. Nossa intenção não foi julgar a qualidade das disciplinas, mas reconhecer e evidenciar que tipo de discussão é proposto e incentivado nessas disciplinas. Reiteramos aqui nossa compreensão de que os documentos analisados constituem um indicativo formal e que realizamos com a intenção de compreender o campo propositivo dos cursos de graduação em LF investigados.

Classificamos uma ementa ou trecho de uma ementa como pertencendo à categoria (i) 'História da(s) Ciência(s)/Física' quando prioriza uma perspectiva de análise de aspectos da natureza da ciência, de um ponto de vista histórico, podendo considerar também fatores sociais, políticos e culturais, por meio de episódios históricos das ciências e da evolução das suas ideias. Esta categoria contém quatro subcategorias. A subcategoria 'Evolução Histórica das Ideias e Conceitos - Fatores Conceituais' se refere à análise a partir de uma visão internalista da história da ciência, pela compreensão de que a estrutura histórica da ciência pode ser entendida e explicada a partir das suas teorias e conceitos. As subcategorias 'Evolução Histórica do Conhecimento Científico - Fatores Extraconceituais' e 'Períodos Históricos - Fatores Extraconceituais' se referem à análise a partir de uma visão externalista da história da ciência, pela compreensão de que a estrutura histórica da ciência pode ser entendida e explicada, ou ainda pautada, para além de critérios não-racionais, considerando também critérios que não estejam vinculados apenas à construção lógica da ciência. Os extratos são classificados na subcategoria 'Evolução Histórica do Conhecimento Científico Fatores Extraconceituais' quando se referem à descrição e debate mais amplo sobre a evolução histórica de fatores extraconceituais, com o estabelecimento de relações entre a história da ciência/física e a filosofia, epistemologia e sociologia da ciência. Já os extratos que se referem a fatos ou períodos da história como elemento de demarcação da evolução histórica da ciência e da física são classificados na subcategoria 'Períodos Históricos Fatores Extraconceituais'. A subcategoria 'Nomes de Cientistas' é atribuída especificamente aos nomes dos cientistas mencionados nas ementas das disciplinas como se referindo aos 
responsáveis pelo desenvolvimento científico de determinados períodos históricos da ciência. Esta categorização é apresentada na Tabela 1.

Tabela 1 - Categoria (i) 'História da(s) Ciência(s)/Física(s)', suas subcategorias, indicadores que orientam a categorização e exemplos de extratos de ementas de disciplinas analisadas.

\begin{tabular}{|c|c|c|}
\hline \multicolumn{3}{|c|}{ CATEGORIA: HISTÓRIA DA(S) CIÊNCIA(S)/FÍSICA } \\
\hline Subcategorias & Indicadores & Exemplos de extratos \\
\hline $\begin{array}{l}\text { Evolução Histórica } \\
\text { das } \\
\text { Ideias/Conceitos - } \\
\text { Fatores Conceituais }\end{array}$ & $\begin{array}{l}\text { Atribuído a extratos que se } \\
\text { referem à descrição e debate } \\
\text { restrito à evolução histórica dos } \\
\text { fatores conceituais, a partir de } \\
\text { uma abordagem internalista da } \\
\text { história da ciência. }\end{array}$ & $\begin{array}{l}\text { "Evolução histórica e epistemológica de } \\
\text { conceitos das ciências e suas influências } \\
\text { na física clássica e moderna." } \\
\text { "Evolução dos conceitos fundamentais } \\
\text { da física do ponto de vista histórico } \\
\text { desde a antiguidade até o nosso século. } \\
\text { (...) Evolução conceitual da relação } \\
\text { "força-movimento" (antiperístases de } \\
\text { Aristóteles, força impressa, impetus e } \\
\text { inércia). Evolução conceitual da } \\
\text { gravitação. Evolução conceitual do } \\
\text { calor." }\end{array}$ \\
\hline $\begin{array}{l}\text { Evolução Histórica } \\
\text { do Conhecimento } \\
\text { Científico - Fatores } \\
\text { Extraconceituais }\end{array}$ & $\begin{array}{l}\text { Atribuído a extratos que se } \\
\text { referem à descrição e debate mais } \\
\text { amplo sobre a evolução histórica } \\
\text { de fatores extraconceituais, com o } \\
\text { estabelecimento de relações entre } \\
\text { a história da ciência/física e a } \\
\text { filosofia, epistemologia e } \\
\text { sociologia da ciência, a partir de } \\
\text { uma abordagem externalista da } \\
\text { história da ciência. }\end{array}$ & $\begin{array}{l}\text { "História da ciência com ênfase nas } \\
\text { principais tendências e paradigmas } \\
\text { teóricos" } \\
\text { "O uso de episódios da história da } \\
\text { ciência para compreensão da ciência } \\
\text { como uma construção humana." } \\
\text { "Análise histórica da ciência através das } \\
\text { principais teorias filosófico-científicas." }\end{array}$ \\
\hline $\begin{array}{l}\text { Períodos } \\
\text { Históricos- Fatores } \\
\text { Extraconceituais }\end{array}$ & $\begin{array}{l}\text { Atribuído a extratos que se } \\
\text { referem a períodos históricos } \\
\text { como elemento de demarcação da } \\
\text { evolução histórica da ciência e da } \\
\text { física, a partir de uma abordagem } \\
\text { externalista da história da ciência. }\end{array}$ & $\begin{array}{l}\text { "Fornecer uma discussão sobre o papel } \\
\text { da física na Revolução Industrial do } \\
\text { início do século XX." }\end{array}$ \\
\hline Nomes de cientistas & $\begin{array}{l}\text { Atribuído a extratos que se } \\
\text { referem aos nomes dos cientistas } \\
\text { como se referissem a fatos ou } \\
\text { períodos históricos. }\end{array}$ & $\begin{array}{l}\text { "Aristóteles, árabes, escolásticos, } \\
\text { Galileu, Newton, Leibnitz e Descartes." } \\
\text { "Descrever as contribuições de } \\
\text { cientistas como Copérnico, Kepler, } \\
\text { Galileu, Descartes e Newton para o } \\
\text { desenvolvimento da Física." } \\
\text { "Faraday, Maxwell e Hertz, Oesterd e } \\
\text { Lenz." }\end{array}$ \\
\hline
\end{tabular}

Fonte: Ferreira (2018) 
Classificamos uma ementa ou trecho de uma ementa como pertencendo à categoria (ii) 'Análise e Estudos das Ideias da Filosofia, Epistemologia, Sociologia da(s) Ciência(s)' quando prioriza uma perspectiva de análise de aspectos da natureza da ciência, de um ponto de vista filosófico e/ou sociológico, avaliando processos e produtos, procedimentos e resultados do trabalho do cientista e da pesquisa científica, de um ponto de vista descritivo, analítico e valorativo. Esta categorização é apresentada na Tabela 2.

Tabela 2 - Categoria (ii) 'Análise e Estudos das Ideias da Filosofia, Epistemologia, Sociologia da(s) Ciência(s)', indicadores que orientam a categorização e exemplos de extratos de ementas de disciplinas analisadas.

\begin{tabular}{|c|c|}
\hline ) & \\
\hline Indicadores & Exemplo de extratos \\
\hline $\begin{array}{l}\text { Atribuído a extratos que se referem à Análise e } \\
\text { Estudo das Ideias da Filosofia, da Epistemologia e } \\
\text { da Sociologia da(s) Ciência(s) e da Física a partir } \\
\text { do enfoque filosófico e sociológico, avaliando } \\
\text { processos e produtos, procedimentos e resultados } \\
\text { do trabalho do cientista e da pesquisa científica, de } \\
\text { um ponto de vista descritivo, analítico e valorativo. }\end{array}$ & $\begin{array}{l}\text { "Progresso da Ciência e da Tecnologia" } \\
\text { "A natureza da ciência, a produção do } \\
\text { conhecimento científico e seus métodos e } \\
\text { procedimentos de validação" } \\
\text { "Pressupostos filosóficos que fundamentam o } \\
\text { pensamento científico" } \\
\text { "Aspectos filosóficos e científicos da Física" }\end{array}$ \\
\hline
\end{tabular}

Fonte: Ferreira (2018)

Classificamos uma ementa ou trecho de uma ementa como pertencendo à categoria (iii) 'Filósofos, Epistemólogos, Sociólogos da(s) Ciência(s)' quando menciona nas ementas das disciplinas apenas os nomes dos filósofos para se referir ao debate sobre filosofia, epistemologia e Sociologia da(s) ciência(s). Esta categorização é apresentada na Tabela 3.

Tabela 3 - Categoria (iii) 'Filósofos, Epistemólogos, Sociólogos da(s) Ciência(s)', suas subcategorias, indicadores que orientam a categorização e exemplos de extratos de ementas de disciplinas analisadas.

\begin{tabular}{|c|c|c|}
\hline \multicolumn{3}{|c|}{ CATEGORIA: FILÓSOFOS, EPISTEMÓLOGOS, SOCIÓLOGOS DA(S) CIÊNCIA(S) } \\
\hline Subcategorias & Indicadores & Exemplos de extratos \\
\hline Bruno Latour & \multirow{7}{*}{$\begin{array}{l}\text { Atribuído às } \\
\text { menções a nomes } \\
\text { de Filósofos, } \\
\text { Epistemólogos e } \\
\text { Sociólogos da(s) } \\
\text { Ciência(s). }\end{array}$} & \multirow{7}{*}{$\begin{array}{l}\text { "As epistemologias do século XX: Popper, } \\
\text { Kuhn, Lakatos, Bachelard, Bunge, } \\
\text { Feyerabend, Toulmin, Laudan". } \\
\text { "Epistemologias do Século XX: Bachelard, } \\
\text { Poincaré, Popper, Kuhn, Feyerabend, } \\
\text { Lakatos, Laudan, Tolmin, Maturana, Bunge e } \\
\text { etc. } \\
\text { "A crítica e o desenvolvimento do }\end{array}$} \\
\hline Ernest Mayr & & \\
\hline $\begin{array}{l}\text { Filósofos, Epistemólogos, } \\
\text { Sociólogos da(s) Ciência(s) }\end{array}$ & & \\
\hline Gaston Bachelard & & \\
\hline Henri Poincaré & & \\
\hline Humberto Maturana & & \\
\hline Ilya Prigogine & & \\
\hline
\end{tabular}




\begin{tabular}{|c|c|}
\hline Imre Lakatos & \multirow{10}{*}{$\begin{array}{l}\text { conhecimento: Popper, Kuhn, Feyerabend, } \\
\text { Bachelard". } \\
\text { "Evolução da ciência: Popper, Kuhn e } \\
\text { Lakatos". } \\
\text { "As ideias de Popper; A Filosofia de Thomas } \\
\text { Kuhn; As Ideias de Lakatos e Feyerabend." } \\
\text { "Modelos de Gaston Bachelard, Karl Popper, } \\
\text { Thomas Kuhn, Imre Lakatos, Paul } \\
\text { Feyerabend, Mário Bunge, Humberto } \\
\text { Maturana e Ilya Prigogine". }\end{array}$} \\
\hline Karl Popper & \\
\hline Larry Laudan & \\
\hline Ludwik Fleck & \\
\hline Mário Bunge & \\
\hline Paul Feyerabend & \\
\hline Pierre Bourdieu & \\
\hline Richard Holton & \\
\hline Stephen Toulmin & \\
\hline Thomas Kuhn & \\
\hline
\end{tabular}

Fonte: Ferreira (2018)

Classificamos uma ementa ou trecho de uma ementa como pertencendo à categoria (iv) 'Temas de Epistemologia, Filosofia e Sociologia da(s) Ciência(s)/Física' quando menciona nas ementas das disciplinas termos que se referem aos debates da epistemologia, filosofia e sociologia da(s) ciência(s) sobre 'demarcação entre ciência e não-ciência', 'explicação', 'justificação', 'neutralidade', 'verdade', entre outros, sem nenhuma outra especificação ou detalhamento. Esta categorização é apresentada na Tabela 4.

Tabela 4 - Categoria (iv) 'Temas de Epistemologia, Filosofia e Sociologia da(s) Ciência(s)/Física', suas subcategorias, indicadores que orientam a categorização e exemplos de extratos de ementas de disciplinas analisadas.

\begin{tabular}{|c|c|c|c|}
\hline \multicolumn{4}{|c|}{$\begin{array}{l}\text { CATEGORIA: TEMAS DE EPISTEMOLOGIA, FILOSOFIA E SOCIOLOGIA } \\
\text { DA(S) CIÊNCIA(S)/FÍSICA }\end{array}$} \\
\hline \multicolumn{2}{|l|}{ Subcategorias } & Indicadores & $\begin{array}{l}\text { Exemplos de } \\
\text { extratos }\end{array}$ \\
\hline $\begin{array}{l}\text { Anarquismo } \\
\text { epistemológico }\end{array}$ & $\begin{array}{l}\text { Neutralidade } \\
\text { científica }\end{array}$ & \multirow{11}{*}{$\begin{array}{l}\text { Atribuído às } \\
\text { menções/extratos } \\
\text { que se referem a } \\
\text { temas de } \\
\text { Epistemologia, } \\
\text { Filosofia e } \\
\text { Sociologia da(s) } \\
\text { Ciência(s), como } \\
\text { menções à critérios } \\
\text { de ordem cognitiva } \\
\text { que conceituem } \\
\text { 'demarcação entre } \\
\text { ciência e não- } \\
\text { ciência', } \\
\text { 'explicação', } \\
\text { 'justificação', } \\
\text { 'neutralidade', } \\
\text { 'verdade', entre }\end{array}$} & \multirow{11}{*}{$\begin{array}{l}\text { "Origem do } \\
\text { pensamento } \\
\text { filosófico. Origem do } \\
\text { pensamento } \\
\text { científico." } \\
\text { "As Origens da } \\
\text { Ciência Clássica." } \\
\text { "A Origem da } \\
\text { Física." } \\
\text { "Conhecimento } \\
\text { científico, método } \\
\text { científico" } \\
\text { "Ética e ciência." } \\
\text { "Valores e ética na } \\
\text { prática científica." } \\
\text { "Paradigmas e } \\
\text { revoluções } \\
\text { científicas. Ruptura }\end{array}$} \\
\hline Anomalias & $\begin{array}{l}\text { Objetividade } \\
\text { científica }\end{array}$ & & \\
\hline Ciência extraordinária & Observação científica & & \\
\hline Ciência normal & $\begin{array}{l}\text { Obstáculos } \\
\text { epistemológicos }\end{array}$ & & \\
\hline Cientificidade & Origem & & \\
\hline $\begin{array}{l}\text { Comensurabilidade/ } \\
\text { incomensurabilidade }\end{array}$ & Paradigma & & \\
\hline $\begin{array}{l}\text { Concepções de } \\
\text { ciência }\end{array}$ & $\begin{array}{l}\text { Pluralismo } \\
\text { metodológico }\end{array}$ & & \\
\hline $\begin{array}{l}\text { Conjecturas e } \\
\text { refutações }\end{array}$ & $\begin{array}{l}\text { Problemas e } \\
\text { problematizações }\end{array}$ & & \\
\hline $\begin{array}{l}\text { Demarcação entre } \\
\text { ciência e não-ciência }\end{array}$ & $\begin{array}{l}\text { Programas de } \\
\text { pesquisa }\end{array}$ & & \\
\hline Empírico-indutivista & Progresso científico & & \\
\hline Espírito científico & Racionalidade & & \\
\hline
\end{tabular}




\begin{tabular}{|c|c|c|c|}
\hline & científica & \multirow[t]{9}{*}{ outros. } & \multirow{9}{*}{$\begin{array}{l}\text { paradigmática e } \\
\text { revolução científica." } \\
\text { "Conhecimento } \\
\text { científico, método } \\
\text { científico, grandes } \\
\text { paradigmas da } \\
\text { ciência." }\end{array}$} \\
\hline Ética e Ciência & Racionalismo crítico & & \\
\hline Experimentação & Relativismo & & \\
\hline Explicação Científica & $\begin{array}{l}\text { Revolução(ões) } \\
\text { científica(s) }\end{array}$ & & \\
\hline Falsificacionismo & Rupturas; & & \\
\hline $\begin{array}{l}\text { Fenômenos } \\
\text { Científicos }\end{array}$ & Tradição científica & & \\
\hline Justificação & Valor(es) e Ciência & & \\
\hline Método científico & Verdade científica & & \\
\hline $\begin{array}{l}\text { Modelos em } \\
\text { Ciência/científico }\end{array}$ & Verificação & & \\
\hline
\end{tabular}

Fonte: Ferreira (2018)

Classificamos uma ementa ou trecho de uma ementa como pertencendo à categoria (v) 'História, Filosofia, Epistemologia e Sociologia da(s) Ciência(s) e da Física para o Ensino' quando prioriza uma discussão sobre usos e implicações metodológicas do debate sobre a natureza da ciência. Esta categoria contém duas subcategorias. A subcategoria 'Uso e implicações da História, Filosofia, Epistemologia e Sociologia da(s) Ciência(s)/Física para o Ensino' se refere à análise a partir de uma visão metodológica da área do ensino de física, contemplando uma descrição e discussão sobre o uso e implicações da história, filosofia, epistemologia e sociologia da(s) ciência(s) e da física no ensino. A subcategoria 'Visões $e$ Concepções sobre Natureza da(s) Ciência(s) no Ensino' se refere à proposta de discussão sobre visões, concepções e imagens de alunos e professores sobre natureza da ciência. Esta categorização é apresentada na Tabela 5.

Tabela 5 - Categoria (v) 'História, Filosofia, Epistemologia e Sociologia da(s) Ciência(s) e da Física para o Ensino', suas subcategorias, indicadores que orientam a categorização e exemplos de extratos de ementas de disciplinas analisadas.

\begin{tabular}{|c|c|c|}
\hline \multicolumn{3}{|c|}{$\begin{array}{l}\text { CATEGORIA: HISTÓRIA, FILOSOFIA, EPISTEMOLOGIA E SOCIOLOGIA DA(S) } \\
\text { CIÊNCIA(S)/FÍSICA PARA O ENSINO }\end{array}$} \\
\hline & & \\
\hline $\begin{array}{l}\text { Uso e Implicações da } \\
\text { História, Filosofia, } \\
\text { Epistemologia e } \\
\text { Sociologia da(s) } \\
\text { Ciência(s)/Física para c } \\
\text { Ensino }\end{array}$ & $\begin{array}{l}\text { Atribuído a extratos que } \\
\text { se referem à descrição e } \\
\text { discussão sobre o uso e } \\
\text { implicações da História, } \\
\text { Filosofia, Epistemologia e } \\
\text { Sociologia da(s) } \\
\text { Ciência(s) e da Física } \\
\text { para o ensino. }\end{array}$ & $\begin{array}{l}\text { "História da ciência no ensino (de física)." } \\
\text { "História e Filosofia da Ciência e ensino } \\
\text { de Física." } \\
\text { "As implicações da história e da } \\
\text { epistemologia da Ciência para o ensino." } \\
\text { "Uso da História e da Filosofia da Ciência } \\
\text { no ensino." } \\
\text { "Importância da história e da filosofia da } \\
\text { ciência para o ensino de ciências naturais." }\end{array}$ \\
\hline $\begin{array}{l}\text { Visões e Concepções } \\
\text { sobre Natureza da(s) }\end{array}$ & $\begin{array}{l}\text { Atribuído a extratos que } \\
\text { se referem às visões ou }\end{array}$ & $\begin{array}{l}\text { "Concepções sobre a natureza da ciência e } \\
\text { sobre a natureza do trabalho científico." }\end{array}$ \\
\hline
\end{tabular}




\begin{tabular}{|l|l|l|}
\hline Ciência(s) no Ensino & $\begin{array}{l}\text { concepções de alunos e } \\
\text { professores sobre } \\
\text { Natureza da(s) Ciência(s). }\end{array}$ & $\begin{array}{l}\text { "Identificar e analisar as concepções de } \\
\text { alunos e professores dos níveis de ensino } \\
\text { médio e superior sobre a Natureza da } \\
\text { ciência e da investigação científica." }\end{array}$ \\
\hline
\end{tabular}

Fonte: Ferreira (2018)

Por fim, classificamos uma ementa ou trecho de uma ementa como pertencendo à categoria (vi) 'Outros' quando propõe o debate sobre natureza da ciência, mas não se localiza em nenhuma das categorias anteriores. Esta categoria contém duas subcategorias. A subcategoria 'Relações de Ciência, Tecnologia, Sociedade e Ambiente' se refere à análise a partir de uma perspectiva do movimento Ciência, Tecnologia e Sociedade (CTS) e Ciência, Tecnologia, Sociedade e Ambiente (CTS) na educação científica. A subcategoria 'Ciência e tipos de conhecimento' é atribuída a extratos que mencionam a discussão sobre a ciência e relação a outros tipos de conhecimento dentro do contexto do debate da natureza da ciência. Esta categorização é apresentada na Tabela 6.

Tabela 6 - Categoria (vi) 'Outros', suas subcategorias, indicadores que orientam a categorização e exemplos de extratos de ementas de disciplinas analisadas.

\begin{tabular}{|c|c|c|}
\hline \multicolumn{3}{|c|}{ CATEGORIA: OUTROS } \\
\hline Subcategorias & Indicadores & Exemplos de extratos \\
\hline $\begin{array}{l}\text { Relações de Ciência, } \\
\text { Tecnologia, Sociedade e } \\
\text { Ambiente }\end{array}$ & $\begin{array}{l}\text { Atribuído a extratos que se } \\
\text { referem à discussão sobre as } \\
\text { relações entre Ciência, } \\
\text { Tecnologia, Sociedade e } \\
\text { Ambiente. }\end{array}$ & $\begin{array}{l}\text { "Aspectos da abordagem Ciência- } \\
\text { Tecnologia-Sociedade (CTS) na } \\
\text { educação científica." } \\
\text { "Aspectos históricos, filosóficos e } \\
\text { sociológicos dos enfoques CTS." }\end{array}$ \\
\hline $\begin{array}{l}\text { Ciência e tipos de } \\
\text { conhecimento }\end{array}$ & $\begin{array}{l}\text { Atribuído a extratos que } \\
\text { mencionam a discussão } \\
\text { sobre a ciência e relação a } \\
\text { outros tipos de } \\
\text { conhecimento dentro do } \\
\text { contexto do debate da } \\
\text { natureza da ciência }\end{array}$ & "Ciência e tipos de conhecimento." \\
\hline
\end{tabular}

Fonte: Ferreira (2018).

\section{V.2 Análise das Ementas}

A codificação dos textos das 390 ementas, de acordo com as categorias/subcategorias descritas anteriormente gerou um quantitativo de 1480 extratos referentes a menções ao estudo da temática da natureza da ciência. Em uma análise quantitativa com relação à ocorrência dos extratos, a categoria (i) 'História da(s) Ciência(s)/Física' obteve o maior número de registros com 536 extratos (36,21\%). Na sequência a categoria (iv) 'Temas de Epistemologia, Filosofia e Sociologia da(s) Ciência(s)/Física' obteve 403 extratos registrados 
(27,22\%). Enquanto as categorias (iii) 'Filósofos, Epistemólogos, Sociólogos da(s) Ciência(s)' e (ii) 'Análise e Estudo das Ideias da Filosofia, Epistemologia, Sociologia da(s) Ciência(s)', obtiveram menor número de ocorrências, com 165 extratos (11,15\%) e 164 extratos $(11,08 \%)$, respectivamente. As categorias com o menor número de menções foram (v) 'História, Filosofia, Epistemologia e Sociologia da(s) Ciência(s)/Física para o Ensino' e (vi) 'Outros', com 131 extratos (8,85\%) e 81 extratos (5,47\%), respectivamente.

Em uma análise quantitativa em relação a ocorrência dos extratos em cada um dos grupos de disciplinas, o grupo que apresenta o maior quantitativo de registros é o que se refere aos SDHFESC/F com 1264 extratos (85,4\%), sendo 1005 em disciplinas de caráter obrigatório e 259 em disciplinas de caráter optativo/eletivo. Já o grupo que se refere aos SP apresenta 160 extratos (10,8\% do total de extratos), sendo 142 em disciplinas de caráter obrigatório e 18 em disciplinas de caráter optativo/eletivo. Enquanto o grupo que se refere aos SDF apresenta 56 extratos (3,8\% do total de extratos), sendo 51 em disciplinas de caráter obrigatório e 5 em disciplinas de caráter optativo/eletivo. Os quantitativos de extratos são apresentados na Tabela 7 na qual são destacadas as categorias e subcategorias mais frequentes, e na Fig. 2 em que são apresentados os percentuais por categoria e grupo de disciplinas.

Tabela 7 - Quantitativo de extratos em cada uma das categorias, classificadas de acordo com SDHFESC/F, SP e SDF e com o caráter de oferta.

\begin{tabular}{|c|c|c|c|c|c|c|c|c|}
\hline \multirow[b]{2}{*}{ CATEGORIAS } & \multicolumn{2}{|c|}{ SDHFESC/F } & \multicolumn{2}{|c|}{ SP } & \multicolumn{2}{|c|}{ SDF } & \multirow{2}{*}{\multicolumn{2}{|c|}{ Total }} \\
\hline & $\begin{array}{l}\text { OB } \\
208\end{array}$ & $\begin{array}{c}\text { OPT } \\
76\end{array}$ & $\begin{array}{c}\text { OB } \\
71\end{array}$ & $\begin{array}{c}\text { OPT } \\
8\end{array}$ & $\begin{array}{l}\text { OB } \\
24\end{array}$ & $\begin{array}{c}\text { OPT } \\
3\end{array}$ & & \\
\hline \multicolumn{9}{|l|}{ História da(s) Ciência(s)/Física } \\
\hline $\begin{array}{l}\text { Evolução Histórica das } \\
\text { Ideias/ Conceitos - Fatores } \\
\text { Conceituais }\end{array}$ & 158 & 44 & 14 & 0 & 22 & 2 & 240 & \multirow{4}{*}{536} \\
\hline $\begin{array}{l}\text { Evolução Histórica do } \\
\text { Conhecimento Científico - } \\
\text { Fatores Extraconceituais }\end{array}$ & 32 & 9 & 2 & 0 & 4 & 1 & 48 & \\
\hline $\begin{array}{l}\text { Períodos Históricos - Fatores } \\
\text { Extraconceituais }\end{array}$ & 161 & 41 & 1 & 0 & 6 & 0 & 209 & \\
\hline \begin{tabular}{l|l} 
Nomes de Cientistas \\
\end{tabular} & 32 & 7 & 0 & 0 & 0 & 0 & 39 & \\
\hline $\begin{array}{l}\text { Temas de Epistemologia, } \\
\text { Filosofia e Sociologia da(s) } \\
\text { Ciência(s)/Física }\end{array}$ & 303 & 65 & 13 & 6 & 16 & 0 & & 403 \\
\hline $\begin{array}{l}\text { Filósofos, Epistemólogos, } \\
\text { Sociólogos da(s) Ciência(s) }\end{array}$ & 127 & 37 & 0 & 0 & 0 & 1 & & 165 \\
\hline $\begin{array}{l}\text { Análise e Estudo das Ideias da } \\
\text { Filosofia, Epistemologia, } \\
\text { Sociologia da(s) Ciência(s) }\end{array}$ & 116 & 39 & 6 & 1 & 1 & 1 & & 164 \\
\hline
\end{tabular}




\begin{tabular}{|c|c|c|c|c|c|c|c|c|}
\hline \multicolumn{9}{|l|}{ HFESC/F para o Ensino } \\
\hline $\begin{array}{l}\text { Uso e Implicações da } \\
\text { História, Filosofia, } \\
\text { Epistemologia e Sociologia } \\
\text { das Ciência(s)/Física para o } \\
\text { Ensino }\end{array}$ & 41 & 9 & 66 & 5 & 2 & 0 & 123 & \multirow[t]{2}{*}{131} \\
\hline $\begin{array}{l}\text { Visões/Concepções sobre } \\
\text { Natureza das Ciências no } \\
\text { Ensino }\end{array}$ & 2 & 0 & 5 & 1 & 0 & 0 & 8 & \\
\hline \multicolumn{9}{|l|}{ Outros } \\
\hline $\begin{array}{l}\text { Relações de Ciência, } \\
\text { Tecnologia, Sociedade e } \\
\text { Ambiente }\end{array}$ & 27 & 3 & 35 & 5 & 0 & 0 & 70 & \multirow[t]{2}{*}{81} \\
\hline $\begin{array}{l}\text { Ciência e tipos de } \\
\text { conhecimento }\end{array}$ & 6 & 5 & 0 & 0 & 0 & 0 & 11 & \\
\hline \multirow[t]{2}{*}{ Total } & 1005 & 259 & 142 & 18 & 51 & 5 & \multicolumn{2}{|c|}{1480} \\
\hline & \multicolumn{2}{|c|}{1264} & \multicolumn{2}{|c|}{160} & \multicolumn{2}{|c|}{156} & & \\
\hline
\end{tabular}

Fonte: Ferreira (2018).

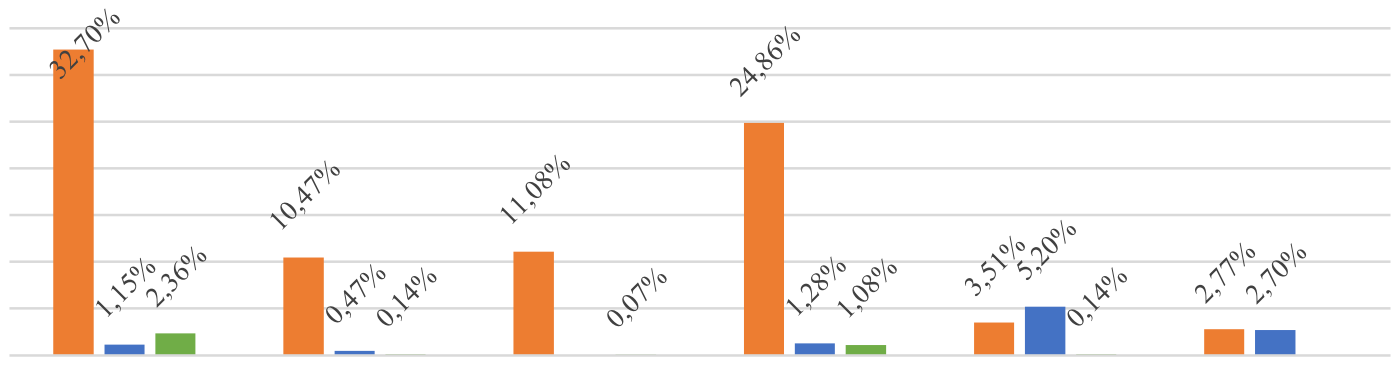
(i) 'História da(s)
(ii) 'Análise e
(iii) 'Filósofos,
(iv) 'Temas de
(v) 'História,
$\begin{array}{cc}\text { Ciência(s)/Física' Estudo das Ideias } & \text { Epistemólogos, } \\ \text { da Filosofia, } & \text { Sociólogos da(s) } \\ \text { Epistemologia, } & \text { Ciência(s)/Física' }\end{array}$
Epistemologia,
Filosofia,
Filosofia e Epistemologia e
Epistemologia,
Sociologia da(s)
Ciência(s)/Física'
Sociologia da(s) Sociologia da(s)
Ciência(s)/Física' Ciência(s)/Física
para o Ensino'

\section{- Percentual de disciplinas classificadas como SDHFESC/F \\ - Percentual de disciplinas classificadas como SP \\ - Percentual de disciplinas classificadas como SDF}

(vi) 'Outros'

Fig. 2 - Frequência dos extratos/trechos das ementas em relação às categorias (rótulos) e aos SDHFESC/F, SP e SDF (barras).

As análises com relação à presença de discussões sobre natureza da ciência levando em consideração as categorias e subcategorias aqui definidas, nas disciplinas classificadas em cada um dos grupos com relação aos saberes serão apresentadas na sequência deste texto, buscando ressaltar pontos de interesse para a caracterização dos contextos em que os cursos de LF se desenvolvem. 


\section{(i) Categoria 'História da(s) Ciência(s)/Física'}

Na categoria 'História da(s) Ciência(s)/Física', o grupo de disciplinas que apresenta maior número de extratos e, consequentemente subcategorias associadas, é o das disciplinas classificadas como SDHFESC/F, representando 32,7\% do total de extratos (484 extratos), seguido das disciplinas classificadas como SDF, representando $2,4 \%$ do total de extratos (35 extratos), e por fim, das disciplinas classificadas como SP, representando $1,1 \%$ do total de extratos (17 extratos).

As subcategorias mais frequentes são 'Evolução Histórica das Ideias/Conceitos Fatores Conceituais' e 'Períodos Históricos - Fatores Extraconceituais' que compõem $83,8 \%$ dos extratos pertencentes a esta categoria e a 30,3\% do total de extratos (449 extratos). Os extratos assim subcategorizados tratam da história da ciência, em particular da física, sem vínculos com aspectos filosóficos, epistemológicos e sociológicos, privilegiando aspectos puramente conceituais ou momentos e períodos históricos dissociados de uma leitura epistemologicamente nutrida e fundamentada. A história da ciência/física, a partir desta perspectiva, é vista como "uma história meramente cronológica, de viés positivista, e muitas vezes vista como um repositório de curiosidades, é uma história pobre" (NICOLODELLI, 2011, p. 99).

Já conteúdos associados a uma perspectiva filosoficamente embasada, representados pela subcategoria 'Evolução Histórica do Conhecimento Científico - Fatores Extraconceituais', estão presentes em apenas 9,0\% dos extratos pertencentes a esta categoria, representando $3,2 \%$ do total de extratos (48 extratos). Os demais extratos, 7,3\% desta categoria e 2,6\% do total (39 extratos), estão associados a menções de 'Nomes de cientistas'.

Esses dados podem indicar que parte dos conteúdos propostos nas ementas das disciplinas sobre história da ciência e da física dos currículos de formação de professores de física de IES públicas no Brasil não estejam apresentando o debate mais amplo sobre a evolução histórica de fatores extraconceituais, com o estabelecimento de relações entre a história da ciência e da física e a filosofia, epistemologia e sociologia da ciência; debate este fortemente recomendado pelos estudos e pesquisas da área (ROSA; MARTINS, 2007; FORATO; PIETROCOLA; MARTINS, 2011; PEREIRA; MARTINS, 2011; NICOLODELLI, 2011; LONDERO, 2015).

(ii) Categoria 'Análise e Estudo das Ideias da Filosofia, Epistemologia, Sociologia da(s) Ciência(s)'

Na categoria 'Análise e Estudo das Ideias da Filosofia, Epistemologia, Sociologia da(s) Ciência(s)', o grupo de disciplinas que apresenta maior número de extratos é o das disciplinas classificadas como SDHFESC/F, representando $7,8 \%$ do total de extratos (116 extratos), seguido das disciplinas classificadas como SP, representando $0,5 \%$ (7 extratos), e por fim, das disciplinas classificadas como SDF, representando 0,1\% (2 extratos). 
Estes dados podem indicar que parte dos conteúdos propostos nas ementas das disciplinas sobre natureza da ciência buscam aprofundamentos nas ideias da filosofia, epistemologia e sociologia da(s) ciência(s), propondo-se a avaliar procedimentos e resultados, bem como processos e produtos do trabalho do cientista e da pesquisa científica de um ponto de vista descritivo, analítico e valorativo. Isto é, há uma preocupação em um pequeno conjunto de disciplinas e cursos, em discussões que visem a avaliar os procedimentos ou resultados da pesquisa científica, enfocando aspectos internos ou externos à construção do conhecimento, sem se basear ou referir a fatos históricos, mas sim em um domínio puramente filosófico. Dentre as questões pertinentes nestas discussões podem ser mencionadas algumas que versam sobre o progresso da ciência e da tecnologia, sobre a natureza da ciência, a produção do conhecimento científico e seus métodos e procedimentos de validação, além de discussões em torno dos pressupostos filosóficos que fundamentam o pensamento científico. O que essas ideias trazem são reflexões sobre "o que deveria ser a ciência" e "como a ciência deveria ser para permitir um melhor conhecimento da natureza" (MARTINS, 1999), se caracterizando assim como um estudo de caráter axiológico metacientífico que pode contribuir para avaliar e orientar o trabalho do cientista.

\section{(iii) Categoria 'Filósofos, Epistemólogos, Sociólogos da(s) Ciência(s)'}

Na categoria 'Filósofos, Epistemólogos, Sociólogos da(s) Ciência(s)', o grupo de disciplinas que apresenta maior número de extratos é o das disciplinas classificadas como SDHFESC/F, representando $11,0 \%$ do total de extratos (164 extratos), seguido das disciplinas classificadas como SDF, representando apenas $0,1 \%$ do total de extratos (1 extrato). As disciplinas classificadas como SP não apresentam nenhum extrato com referência a esta categoria. Dentre os filósofos, epistemólogos e sociólogos da(s) ciência(s), os mais mencionados são 'Karl Popper', 'Thomas Kuhn', 'Imre Lakatos', 'Paul Feyerabend', 'Gaston Bachelard'. Com menor número de menções estão 'Mário Bunge' e 'Stephen Toulmin', 'Larry Laudan', 'Bruno Latour' e 'Humberto Maturana', 'Ludwik Fleck', 'Ernest Mayr', 'Henri Poincaré', 'Ilya Prigogine', 'Pierre Bourdieu' e 'Richard Holton'. Há ainda menções para o estudo de filósofos, epistemólogos e sociólogos da(s) ciência(s) em geral, sem especificar os nomes ou correntes filosóficas as quais pertencem. Os quantitativos de extratos são apresentados na Tabela 8 .

Tabela 8 - Quantitativo de extratos categorizados como 'Filósofos, Epistemólogos, Sociólogos da(s) Ciência(s)', com relação aos SDHFESC/F, SP e SDF e em relação ao caráter de oferta.

\begin{tabular}{|l|c|c|c|c|c|c|c|}
\hline \multirow{2}{*}{$\begin{array}{l}\text { Filósofos/Epistemólogos/Soció } \\
\text { logos da(s) Ciência(s) }\end{array}$} & \multicolumn{2}{|c|}{ SDHFESC/F } & \multicolumn{2}{|c|}{ SP } & \multicolumn{2}{|c|}{ SDF } & \multirow{2}{*}{ Total } \\
\cline { 2 - 8 } & OB & OPT & OB & OPT & OB & OPT & \\
\hline Bruno Latour & 3 & 0 & 0 & 0 & 0 & 0 & 3 \\
\hline Ernest Mayr & 1 & 0 & 0 & 0 & 0 & 0 & 1 \\
\hline
\end{tabular}




\begin{tabular}{|l|c|c|c|c|c|c|c|}
\hline $\begin{array}{l}\text { Filósofos, Epistemólogos, } \\
\text { Sociólogos da(s) Ciência(s) } \\
\text { (geral) }\end{array}$ & 14 & 6 & 0 & 0 & 0 & 0 & 20 \\
\hline Gaston Bachelard & 13 & 1 & 0 & 0 & 0 & 0 & 14 \\
\hline Henri Poincaré & 1 & 0 & 0 & 0 & 0 & 0 & 1 \\
\hline Humberto Maturana & 2 & 1 & 0 & 0 & 0 & 0 & 3 \\
\hline Ilya Prigogine & 0 & 1 & 0 & 0 & 0 & 0 & 1 \\
\hline Imre Lakatos & 14 & 7 & 0 & 0 & 0 & 0 & 21 \\
\hline Karl Popper & 21 & 9 & 0 & 0 & 0 & 1 & 31 \\
\hline Larry Laudan & 6 & 0 & 0 & 0 & 0 & 0 & 6 \\
\hline Ludwik Fleck & 2 & 0 & 0 & 0 & 0 & 0 & 2 \\
\hline Mário Bunge & 6 & 1 & 0 & 0 & 0 & 0 & 7 \\
\hline Paul Feyerabend & 14 & 3 & 0 & 0 & 0 & 0 & 17 \\
\hline Pierre Bourdieu & 1 & 0 & 0 & 0 & 0 & 0 & 1 \\
\hline Richard Holton & 1 & 0 & 0 & 0 & 0 & 0 & 1 \\
\hline Stephen Toulmin & 21 & 0 & 0 & 0 & 0 & 0 & 7 \\
\hline Thomas Kuhn & $\mathbf{1 2 7}$ & $\mathbf{3 7}$ & $\mathbf{0}$ & $\mathbf{0}$ & $\mathbf{0}$ & $\mathbf{1}$ & $\mathbf{1 6 5}$ \\
\hline
\end{tabular}

Fonte: Ferreira (2018).

A reflexão epistemológica moderna, presente nas ideias dos filósofos Thomas Kuhn, Karl Popper, Imre Lakatos, Paul Feyerabend e Gaston Bachelard, é bastante frequente para a compreensão do processo de produção e constituição da ciência e do conhecimento científico. Apesar de distintas interpretações epistemológicas deste processo, compartilham da ideia de negação de uma concepção de ciência baseada em um método científico como maneira universal de revelar a realidade dos fenômenos e de produzir conhecimento, entendido como linear e cumulativo. Na educação científica, em particular nos cursos de LF, abordar as ideias destes pensadores, associada a discussões sobre suas implicações no ensino de ciências e de física, é uma escolha muito comum. A área de pesquisa tem se dedicado a compreender como estas ideias sobre a produção do conhecimento podem representar um importante referencial para o trabalho do professor nas aulas de ciências. Em 1996, Delizoicov defendia que se forem devidamente consideradas as proposições destes autores pelo menos duas interpretações muito difundidas na prática educativa sofrem profundas alterações:

A primeira diz respeito ao status do conhecimento cientifico: ele passa a ser concebido como uma verdade histórica e não mais como a verdade extraída dos fatos. Portanto, desmistifica a visão de Ciência pronta, acabada e imutável. A segunda é que a apropriação de conhecimentos científicos pelos alunos não ocorre por simples transmissão dos conceitos, modelos e teorias, uma vez que esta perspectiva epistemológica tem como pressuposto a construção de conhecimento também pelo aluno a partir das suas interações não neutras com objetos de conhecimento. (DELIZOICOV, 1996, p. 183, destaques do autor). 
São inegáveis as significativas contribuições destes pensadores, para descrição, explicação e reflexão sobre a atividade científica e o processo de construção de conhecimento em ciências. Assim como é inegável o aporte que suas epistemologias ofereceram para compreensão do processo de aquisição do conhecimento científico por estudantes, em diferentes níveis de escolaridade. No entanto, o que chama a atenção, no que diz respeito aos cursos de LF, é que embora se tenha avançado com novas perspectivas sobre a produção do conhecimento científico (por exemplo, Giere (1990), Hacking (2012), Longino (1996)), ainda é marcante a presença das ideias dos filósofos, epistemólogos e sociólogos considerados 'canônicos'. Isto nos leva a considerar que os cursos de LF, até o momento, não propuseram a transição do moderno para o contemporâneo em termos de epistemologia.

\section{Ciência(s)/Física'}

(iv) Categoria 'Temas de Epistemologia, Filosofia, Sociologia da(s)

$\mathrm{Na}$ categoria 'Temas de Epistemologia, Filosofia, Sociologia da(s) Ciência(s)/Física', o grupo de disciplinas que apresenta maior número de extratos é o das disciplinas classificadas como SDHFESC/F, representando $24,9 \%$ do total de extratos (368 extratos), seguido das disciplinas classificadas como SP, representando $1,3 \%$ do total de extratos (19 extratos), e por fim, das disciplinas classificadas como SDF, representando 1,1\% do total de extratos (16 extratos). Os quantitativos de extratos são apresentados na Tabela 9.

Tabela 9 - Quantitativo de extratos categorizados como 'Temas de Epistemologia, Filosofia, Sociologia da(s) Ciência(s)/Física', com relação aos SDHFESC/F, SP e SDF e em relação ao caráter de oferta.

\begin{tabular}{|l|c|c|c|c|c|c|c|}
\hline $\begin{array}{l}\text { Temas de Epistemologia, } \\
\text { Filosofia e Sociologia da(s) } \\
\text { Ciência(s)/Física }\end{array}$ & \multicolumn{2}{|c|}{ SDHFESC } & \multicolumn{2}{|c|}{ SP } & \multicolumn{2}{c|}{ SDF } & \multirow{2}{*}{ Total } \\
\cline { 2 - 7 } & OB & OPT & OB & OPT & OB & OPT & \\
\hline Anarquismo Epistemológico & 4 & 1 & 0 & 0 & 0 & 0 & 5 \\
\hline Anomalias & 1 & 0 & 0 & 0 & 0 & 0 & 1 \\
\hline Ciência Extraordinária & 1 & 0 & 0 & 0 & 0 & 0 & 1 \\
\hline Ciência Normal & 2 & 0 & 0 & 0 & 0 & 0 & 2 \\
\hline Cientificidade & 4 & 2 & 0 & 0 & 0 & 0 & 6 \\
\hline $\begin{array}{l}\text { Comensurabilidade e } \\
\text { Incomensurabilidade }\end{array}$ & 2 & 0 & 0 & 0 & 0 & 0 & 2 \\
\hline Concepções de ciência & 7 & 2 & 2 & 3 & 0 & 0 & 14 \\
\hline Conjecturas e Refutações & 1 & 0 & 0 & 0 & 1 & 0 & 2 \\
\hline $\begin{array}{l}\text { Demarcação entre Ciência e } \\
\text { Não-Ciência }\end{array}$ & 2 & 0 & 0 & 0 & 0 & 0 & 2 \\
\hline Empírico-indutivista & 10 & 6 & 0 & 0 & 0 & 0 & 16 \\
\hline Espírito Científico & 1 & 0 & 0 & 0 & 0 & 0 & 1 \\
\hline Ética e Ciência & 27 & 3 & 0 & 0 & 0 & 0 & 30 \\
\hline Experimentação & 11 & 3 & 0 & 1 & 4 & 0 & 19 \\
\hline Explicação Científica & 5 & 2 & 1 & 0 & 0 & 0 & 8 \\
\hline Falsificacionismo & 1 & 1 & 0 & 0 & 0 & 0 & 2 \\
\hline
\end{tabular}




\begin{tabular}{|l|c|c|c|c|c|c|c|}
\hline Fenômenos Científicos & 3 & 0 & 0 & 0 & 1 & 0 & 4 \\
\hline Justificação & 4 & 0 & 0 & 0 & 0 & 0 & 4 \\
\hline Método Científico & 41 & 14 & 3 & 1 & 1 & 0 & 60 \\
\hline Modelos em Ciência/Científico & 6 & 3 & 2 & 0 & 4 & 0 & 15 \\
\hline Neutralidade Científica & 5 & 0 & 0 & 1 & 0 & 0 & 6 \\
\hline Objetividade Científica & 3 & 3 & 0 & 0 & 0 & 0 & 6 \\
\hline Observação Científica & 5 & 1 & 0 & 0 & 0 & 0 & 6 \\
\hline Obstáculos Epistemológicos & 3 & 0 & 0 & 0 & 0 & 0 & 3 \\
\hline Origem & 89 & 14 & 0 & 0 & 2 & 0 & 105 \\
\hline Paradigmas & 29 & 5 & 2 & 0 & 3 & 0 & 39 \\
\hline Pluralismo Metodológico & 3 & 0 & 0 & 0 & 0 & 0 & 3 \\
\hline Problemas e problematizações & 0 & 0 & 1 & 0 & 0 & 0 & 1 \\
\hline Programas de Pesquisa & 10 & 0 & 0 & 0 & 0 & 0 & 10 \\
\hline Progresso Científico & 6 & 1 & 0 & 0 & 0 & 0 & 7 \\
\hline Racionalidade Científica & 7 & 1 & 0 & 0 & 0 & 0 & 8 \\
\hline Racionalismo Crítico & 1 & 0 & 0 & 0 & 0 & 0 & 1 \\
\hline Relativismo & 0 & 0 & 0 & 0 & 0 & 0 & 0 \\
\hline Revolução(ões) Científica(s) & 12 & 4 & 1 & 0 & 2 & 0 & 19 \\
\hline Rupturas & 3 & 0 & 1 & 0 & 0 & 0 & 4 \\
\hline Tradição Científica & 1 & 0 & 0 & 0 & 0 & 0 & 1 \\
\hline Valor(es) e Ciência & 10 & 0 & 1 & 0 & 0 & 0 & 11 \\
\hline Verdade Científica & 2 & 3 & 0 & 0 & 0 & 0 & 5 \\
\hline Verificação & 0 & 0 & 0 & 0 & 0 & 0 & 0 \\
\hline Total & 322 & 69 & 14 & 6 & 18 & 0 & 429 \\
\hline
\end{tabular}

Fonte: Ferreira (2018).

Parte dos termos definidos como 'Temas de Epistemologia, Filosofia e Sociologia da(s) Ciência(s)/Física' podem ser associados às ideias dos filósofos da ciência mais presentes no debate sobre a origem, desenvolvimento e consolidação da ciência na educação científica. Entre os códigos, por ordem de frequência, estão: 'Paradigmas', 'Revolução(ões) Científica(s)', 'Rupturas', 'Ciência Normal', 'Comensurabilidade e Incomensurabilidade', 'Anomalias' e 'Ciência Extraordinária', presentes nas ideias de Thomas Kuhn; 'Programas de Pesquisa', presente nas ideias de Imre Lakatos; 'Pluralismo Metodológico' e 'Anarquismo Epistemológico', presentes nas ideias de Paul Feyerabend; 'Conjecturas e Refutações' e 'Falsificacionismo', presentes nas ideias de Karl Popper; 'Espírito Científico' e 'Obstáculos Epistemológicos', presente nas ideias de Gaston Bachelard. Portanto, 23,3\% dos extratos (93 extratos) desta categoria são temas associados às ideias dos cinco filósofos mais mencionados nas ementas das disciplinas (vide categoria (iii)) que apresentam debate sobre natureza da ciência em cursos de LF de IES públicas no Brasil.

O aparecimento nas MC dos cursos de LF dos temas 'Origem' e 'método científico', que são os mais representativos da categoria, é coerente com as sugestões da literatura da área. A temática da origem, desenvolvimento e consolidação do conhecimento científico, representado em nossa classificação pelos 105 extratos com o termo 'Origem', aparece relacionado como conteúdo de debate sobre a natureza da ciência na proposta de Temas e 
Questões de Martins (2015). Nesta abordagem, o autor propõe que o tema da origem seja debatido a partir de um eixo que denomina epistemológico por meio de questões que dizem respeito a discussão sobre sujeito(s) e objeto(s) do conhecimento científico; a disputa entre conhecimento empírico versus conhecimento teórico; ao papel da observação, experimentação, lógica; argumentos racionais e pensamento teórico; as influências teóricas sobre observações e experiências.

Já a referência à ideia de métodos e metodologia científica, representado em nossa classificação pelos 60 extratos com o termo 'Método Científico' aparece como conteúdo de debate sobre a natureza da ciência na visão consensual da natureza da ciência em trabalhos de Osborne et al. (2001), McComas, Clough e Almazroa (1998) e Lederman et al. (2001), nas propostas de Características da Ciência de Matthews (2012), de Natureza da Ciência 'Completa' de Allchin (2011), de Semelhança de Família de Irzik e Nola (2011), de Campos Teóricos Estruturantes de Adúriz-Bravo (2007), e de Temas e Questões de Martins (2015). Na visão consensual aparece como princípios declarativos, enunciados da seguinte forma: 'Método Científico e Teste Crítico' (OSBORNE et al., 2001), 'Não existe uma única via para a ciência (portanto, não existe um método científico universal passo a passo)' (McCOMAS; CLOUGH; ALMAZROA, 1998) e 'O mito do método científico' (LEDERMAN et al., 2002).

Dentre autores que apresentam propostas renovadas para o debate da natureza da ciência, Allchin (2011) propõe como itens de avaliação dos 'Métodos de investigação' da ciência as seguintes dimensões da confiabilidade da Natureza da Ciência 'Completa': experimento controlado (uma variável), estudos ocultos e de dupla ocultação, análise estatística do erro, replicação e tamanho da amostra, correlação versus causas. Irzik e Nola (2011) propõem como um dos elementos de semelhança familiar o debate sobre 'métodos e regras metodológicas'. Adúriz-Bravo (2007) propõe como uma questão metateórica clássica referente à intervenção e metodologias da ciência, enunciada da seguinte forma: 'Como se faz para dar validade ao conhecimento científico?'. Martins (2015) propõe como 'Métodos, procedimentos e processos da ciência', a ser debatido a partir do eixo epistemológico por meio das questões que dizem respeito à discussão sobre coleta, interpretação, análise e avaliação dos dados; modelagem; observação e inferência; hipóteses, previsões e testes; natureza da explicação científica; avaliação de teorias; o papel das analogias, imaginação e criatividade; a visão do senso comum sobre o método científico.

\section{(v) Categoria 'História, Filosofia, Epistemologia e Sociologia da(s) Ciência(s)/Física para} o Ensino'

Na categoria 'História, Filosofia, Epistemologia e Sociologia da(s) Ciência(s)/Física para o Ensino' foram formadas duas subcategorias. Na subcategoria 'Uso e Implicações da História, Filosofia, Epistemologia e Sociologia da(s) Ciência(s)/Física para o Ensino’ foram registrados 123 extratos (8,3\%). Já na subcategoria 'Visões/Concepções sobre Natureza da(s) Ciência(s) no Ensino' foram registrados 8 extratos (0,5\%). O grupo de disciplinas que 
apresenta maior número de extratos e, consequentemente subcategorias associadas, é o das disciplinas classificadas como SP, representando 5,2\% do total de extratos (77 extratos), seguido das disciplinas classificadas como SDHFESC/F, representando 3,5\% do total de extratos (52 extratos), e por fim das disciplinas classificadas como SDF, representando apenas $0,1 \%$ do total de extratos ( 2 extratos).

A maior frequência de extratos referentes a esta categoria classificados como SP se justifica tendo em vista que grande parte destas disciplinas - de práticas de ensino a estágios de docência - tem como objetivo possibilitar aos estudantes conhecimento básico sobre metodologias e estratégias de ensino de ciências e de física, bem como sobre temáticas da área de pesquisa do seu ensino. Portanto, aparentemente, alguma parcela das reflexões realizadas nas abordagens teórico-metodológicas sobre o debate da natureza da ciência tem sido incorporada nas MC dos cursos de LF. Nestas abordagens, frequentemente, a referência à incorporação do debate sobre a natureza da ciência é proposta nas considerações pedagógicas para o ensino, bem como na reflexão sobre o papel específico da natureza da ciência na formação de professores de ciências (MARTINS, 2007). Já a referência a visões e concepções sobre a natureza da ciência está presente nos instrumentos desenvolvidos para mapear e avaliar as visões de estudantes e professores, originados com testes de variação de concordância desde as perspectivas mais clássicas (como desenvolvidos por ABD-ELKHALICK; LEDERMAN, 2000; LEDERMAN et al., 2001; SCHWARTZ; LEDERMAN; CRAWFORD, 2000), até as análises de episódios históricos e controvérsias científicas mais contemporâneas (como sugerido por GATTI; NARDI; SILVA; 2004; ADÚRIZ-BRAVO, 2007; FERREIRA; MARTINS, 2012; MARTINS, 2015).

Analisando os dados de nossa investigação, à luz das abordagens teóricometodológicas no que diz respeito às considerações pedagógicas e na importância destas reflexões para o ensino de ciências/física, fica perceptível que o debate ocupa um espaço ainda muito restrito nos cursos de formação de professores. Tanto em disciplinas classificadas como SDHFESC/F, quanto como nas classificadas como SP (8,8\% do total de extratos), que se dedicam à discussão específica da natureza da ciência e do ensino da ciência e de física, respectivamente, o aprofundamento sobre o quê, para quê, por quê e como ensinar no que diz respeito à natureza da ciência nos parece essencial para o início de um debate mais qualificado sobre a temática. Além do mais, as indicações presentes nas ementas reduzidas a usar a história, filosofia, epistemologia e sociologia da ciência e física no ensino pode levar a interpretações tão diversas que possivelmente não deem conta da complexidade dos temas e questões inerentes a essa discussão e que perpassam não apenas o ensino de ciências, mas também a própria construção da ciência.

Convém destacar que a presença da dimensão histórica, filosófica e epistemológica na formação de professores de ciências como uma "necessidade formativa do professor" (MARTINS, 2007, p. 115) contribui para "evitar visões distorcidas sobre o fazer científico; permite uma compreensão mais refinada dos diversos aspectos envolvendo o processo de 
ensino aprendizagem da ciência; e proporciona uma intervenção mais qualificada em sala de aula" (MARTINS, 2007, p. 115). Contudo, Martins (2007) reitera que a simples consideração de elementos históricos e filosóficos na formação inicial de professores das áreas científicas ainda que feita com qualidade - não garante a inserção desses conhecimentos nas salas de aula do Ensino Básico, tampouco uma reflexão mais aprofundada, por parte dos professores, do papel da HFC para o campo da didática das ciências. Segundo Martins, "as principais dificuldades surgem quando pensamos na utilização da HFC para fins didáticos, ou seja, quando passamos dos cursos de formação inicial para o contexto aplicado do ensino e aprendizagem das ciências" (2007, p. 115). Isto demonstra que o espaço, atualmente restrito nas MC dos cursos de LF, para discussão da transposição dos conteúdos do debate sobre a natureza da ciência para o ensino precisa ser expandido, a fim de contribuir para mitigar dificuldades, como as acenadas por Martins.

\section{(vi) Categoria 'Outros'}

$\mathrm{Na}$ categoria 'Outros' foram formadas duas subcategorias. $\mathrm{Na}$ subcategoria 'Relações de Ciência, Tecnologia, Sociedade e Ambiente' foram registrados 70 extratos (4,7\%). Já na subcategoria 'Ciência e tipos de conhecimentos' foram registrados 11 extratos $(0,7 \%)$. O grupo de disciplinas que apresenta maior número de extratos e, consequentemente subcategorias associadas, é o das disciplinas classificadas como SDHFESC/F, representando $3,0 \%$ do total de extratos (45 extratos), seguido das disciplinas classificadas como SP, representando $2,2 \%$ do total de extratos (33 extratos). As disciplinas classificadas como SDF não apresentam nenhum extrato com referência a esta categoria.

$\mathrm{Na}$ literatura sobre o debate da natureza da ciência, a temática CTSA aparece relacionada como conteúdo de debate sobre a natureza da ciência na visão consensual da natureza da ciência em trabalhos de Osborne et al. (2001), McComas e Olson (1998) e McComas, Clough e Almazroa (1998), nas propostas de Características da Ciência de Matthews (2012) e de Temas e Questões de Martins (2015). Na abordagem da visão consensual aparece como princípios declarativos, enunciados da seguinte forma: 'Ciência e Tecnologia' (OSBORNE et al., 2001), 'Ciência joga um importante papel na tecnologia' (McCOMAS; OLSON, 1998), 'Ciência e tecnologia se impactam mutuamente' (MCCOMAS CLOUGH; ALMAZROA, 1998). Na abordagem das Características da Ciência aparecem como itens, os quais: 'valores e questões sócio científicas' e 'tecnologia' (MATTHEWS, 2012). Na abordagem dos Temas e Questões aparece como conteúdo a ser debatido no eixo sociológico, histórico e epistemológico questionando o papel do contexto social nessa relação, a interrelação entre ciência e tecnologia, como o conhecimento científico incorpora o conhecimento tecnológico (MARTINS, 2015). A referência aos conteúdos 'Relações de Ciência, Tecnologia e Sociedade' aparece com maior frequência em disciplinas classificadas como SP, o que pode ser influência da tradição do debate do Movimento CTS no contexto da educação científica. 
Já a referência à ciência e diferentes tipos de conhecimento aparece como conteúdo de debate sobre a natureza da ciência nas propostas dos Campos Teóricos Estruturantes de Adúriz-Bravo (2007) e de Temas e Questões de Martins (2015). Na abordagem dos Campos Teóricos Estruturantes aparece como uma questão metateórica clássica referente à estrutura e demarcação da ciência, enunciada da seguinte forma: ' $\mathrm{O}$ que distingue a ciência de outros tipos de conhecimento e de atividades?' (ADÚRIZ-BRAVO, 2007). Na abordagem de Temas e Questões aparece como conteúdo a ser debatido a partir do eixo sociológico, histórico e epistemológico por meio de questões sobre a possibilidade de diferenciação entre ciência e outras formas de conhecimento; características relevantes para essa diferenciação ao longo da história, seja em termos de sujeitos e objetos de conhecimento, bem como em termos de métodos e procedimentos; a influência do contexto social nessa diferenciação; a ciência como visão de mundo; a relação entre os métodos e procedimentos da ciência e grau de confiabilidade do conhecimento científico (MARTINS, 2015).

\section{Considerações finais}

A análise documental dos PPC e MC, focando as ementas das disciplinas que apresentam o debate sobre a natureza da ciência nos cursos de formação de professores de física, de IES do Brasil, realizada possibilitou uma caracterização densa da proposição do debate para grande parte dos cursos de LF no país. Esta análise demonstrou que a inserção de temas relativos à natureza da ciência ainda é muito tímida nos cursos de LF, e estão presentes em ementas de disciplinas que representam apenas $4,65 \%$ da carga horária total dos cursos.

Com base no conteúdo das ementas, classificamos as disciplinas em três grupos, e evidenciamos que o debate da natureza da ciência está presente mais frequentemente em disciplinas específicas sobre o debate histórico, filosófico, epistemológico e sociológico da ciência, que denominamos SDHFESC/F; perpassam parte das disciplinas que abordam aspectos metodológicos do ensino de ciências e de física, que denominamos de SP; e ainda está pouco presente nas disciplinas que abordam especificamente o debate conceitual da ciência e da física, que denominamos de SDF. Neste último conjunto de disciplinas, tradicionalmente se privilegia o conhecimento dos conteúdos e dos métodos da ciência, isto é, o 'conhecimento em ciência' (CUTRERA, 2003). Neste sentido, um ensino através dos produtos finais da ciência tem como objetivo incrementar o conhecimento sobre os êxitos científicos (ADÚRIZ-BRAVO; IZQUIERDO; ESTANY, 2002), e a imagem de uma ciência aproblemática, descontextualizada e fragmentada. A expectativa é de que menções a aspectos que sugerissem uma abordagem da natureza da ciência em disciplinas pertencentes a este grupo talvez pudessem indicar uma mudança de objetivos de um ensino que também fosse 'sobre ciência'.

Portanto, uma mudança de objetivos poderia acarretar ou proporcionar outra perspectiva ou nível de compreensão científica e reflexão referindo-se ao conhecimento sobre como a ciência é feita, como os cientistas desenvolvem, utilizam e deliberam sobre o 
conhecimento científico, isto é, um 'conhecimento sobre ciência' (CUTRERA, 2003) e sobre os processos que levaram à construção da ciência e sobre o fortalecimento do estatuto científico. Acreditamos que para isto acontecer, pelo menos duas características dos cenários do debate sobre a natureza da ciência nos cursos de LF precisam ser alteradas. Primeiro, deve ocorrer a ampliação de carga horária de disciplinas que proponham discutir a natureza da ciência. Segundo, deve ocorrer distribuição desta discussão de forma mais homogênea e integrada entre as disciplinas SDHFESC/F, SP e SDF. Embora estas atitudes sejam fundamentalmente de ordem quantitativa, podem gerar bons efeitos qualitativos na formação dos professores de física.

Consideramos que estes três eixos de disciplinas são complementares e tratar a natureza da ciência de forma isolada em cada uma delas pode dificultar sua compreensão e transposição de seus conteúdos para o ensino. Geralmente, as disciplinas do tipo SDHFESC/F não debatem a didatização e não se articulam com as disciplinas de SDF. Já as disciplinas do tipo SDF, que constituem boa parte dos currículos, abordam conceitos sem se preocupar com sua origem ou contexto de produção, bem como se afastam da didatização. Por sua vez, as disciplinas do tipo SP tratam o a natureza da ciência e os conceitos científicos como objetos a serem ensinados, e os descaracterizam para se tornarem ensináveis. Cada um dos tipos de disciplinas oferece vantagens e desvantagens no tratamento do tema natureza da ciência, portanto o debate sobre a natureza da ciência pode ter maior qualidade se estiver presente nos três eixos e de forma integrada.

Martins (2007) argumenta que a presença de disciplinas de história e filosofia da ciência nas licenciaturas pode contribuir desde que se reflita sobre como inseri-la nos currículos. $\mathrm{O}$ autor detectou em sua investigação sobre as principais dificuldades e experiências no uso da história e filosofia da ciência para fins didáticos, que a maioria dos professores da Educação Básica não percebe de forma clara seu uso como facilitadora da compreensão da própria ciência, limitando-se a considerá-la apenas como conteúdo em si. Nesse sentido, afirma que "de nada adianta o conhecimento do conteúdo (ainda que esse conteúdo seja o histórico e filosófico) sem o conhecimento pedagógico do conteúdo" (MARTINS, 2007, p. 127) e defende a importância de abordar esse debate metodológico nos currículos das licenciaturas, integrado, inclusive, a outras áreas do conhecimento, como pedagogia e história. Nossos dados apontaram que da pequena parcela de carga horária destinada ao debate da natureza da ciência nos LF, 3,39\% são em disciplinas SDHFESC/F, 0,94\% em disciplinas SP e 0,32\% em disciplinas SDF, o que demonstra, além do baixo destaque do tema, ainda haver, tal como Martins sugeriu, maior foco em disciplinas de história e filosofia da ciência e pouca ênfase nas contribuições para o ensino e na produção de material didático.

A análise realizada em termos da frequência de diferentes termos referentes a elementos que sugerem o debate da natureza da ciência nos permitiu evidenciar que, ainda que seja apenas a nível propositivo, e que a decisão didático-metodológica por uma 
abordagem ou outra dependa essencialmente do professor, parte das ementas das disciplinas sugerem um tratamento mais tradicional e conservador sobre a natureza da ciência, enquanto outras ementas das disciplinas atendem a algumas recomendações da literatura para o debate da natureza da ciência na educação científica. No que diz respeito à 'História da(s) Ciência(s)/Física', apesar das recomendações para um debate voltado às relações entre a história da ciência e da física e à filosofia, epistemologia e sociologia da ciência, identificamos nas ementas, a nível propositivo, menções a uma abordagem internalista da história da ciência, dissociada das análises epistemológicas recomendadas. Pereira e Martins (2011), Rosa e Martins (2007), Nicolodelli (2011) e Londero (2015), já sinalizaram que em grande parte das licenciaturas, a história da ciência não se apresenta de maneira articulada ao debate filosófico e epistemológico, ou ainda, o debate filosófico não tem conexão com aspectos históricos.

Com relação aos 'Temas de Epistemologia, Filosofia e Sociologia da(s) Ciência(s)/Física' e aos 'Filósofos, Epistemólogos e Sociólogos da(s) Ciência(s)', algumas temáticas são fortemente recomendadas tanto pela perspectiva consensual, quanto pelas perspectivas renovadas da natureza da ciência e estão presentes nos currículos das LF, como, por exemplo, 'Origem' e 'método científico'. Por outro lado, muito destaque é dado à discussão dos filósofos Thomas Kuhn, Karl Popper, Imre Lakatos, Paul Feyerabend e Gaston Bachelard, considerados canônicos, e aos temas associados às suas obras. Aparentemente o impacto que tiveram na compreensão da ciência e na renovação do ensino de ciências acaba impondo-os como um pré-requisito para qualquer discussão epistemológica mais contemporânea. Adicionalmente, concentra a discussão no tema progresso científico, e, em termos cognitivos, na mudança conceitual dos estudantes. Sugerimos que epistemologias mais contemporâneas figurem nos currículos de LF, pois abrangem outras perspectivas e enfoques.

Em síntese, a análise destas ementas permite constatar que há uma diversidade de temas e conteúdos que constituem os programas das disciplinas que se propõem a abordar a temática da natureza da ciência nos cursos de formação de professores de física no Brasil, e, portanto, 'não há modelos consensuais', como já apontava Prado (1989). Por outro lado, tem ocorrido nos últimos anos um crescente clamor da área de pesquisa na educação científica, em prol do desenvolvimento e construção de concepções sobre ciência, sua origem, essência, progresso e consolidação a partir de perspectivas mais renovadas e ventiladas. É de se esperar, conforme os dados apontam, que estas ideias estejam, pelo menos parcialmente, sendo incorporadas também nos cursos de formação de professores, particularmente, nos eixos formativos SDHFESC/F e SP.

Por fim, gostaríamos de ressaltar que apesar de os cursos de formação de bacharéis não terem sido o principal contexto de investigação desta pesquisa, constatamos que muitas das disciplinas que discutem aspectos da natureza da ciência são obrigatórias para os cursos de LF, porém de caráter optativo para os cursos de Bacharelado em Física. Tal distinção sugere que há maior valorização da temática da natureza da ciência na formação de 
professores do que de bacharéis. Isto pode ter claro reflexo na formação de professores, tendo em vista que, tomados os dados de quantitativos de docentes atuantes em cursos de física disponíveis nas páginas dos departamentos de ensino de instituições de ensino superior públicas, por exemplo, a maioria é de bacharéis, e a tendência é que continue sendo, tendo em vista os editais de contratação de professores do magistério superior, que valorizam determinado perfil formativo voltado à pesquisa (DELIZOICOV, 2012). Segundo Nicolodelli (2011, p. 99), “com lacunas de cunho epistemológico em sua formação, não é de surpreender que esses profissionais propaguem em seu ensino visões de ciência incompatíveis com a filosofia da ciência contemporânea", podendo trazer reflexos, inclusive, para a Educação Básica, levando em consideração que muitos bacharéis podem acabar atuando nesse nível de ensino.

\section{Referências bibliográficas}

ABD-EL-KHALICK, F. Examining the sources for our understandings about science: enduring conflations and critical issues in research on nature of science in science education. International Journal of Science Education, v. 34, n. 3, p. 353-374, 2012 a.

ABD-EL-KHALICK, F. Nature of science in science education: toward a coherent framework for synergistic research and development. In: FRASER, B. J.; TOBIN, K; McROBBIE, C. (Eds.). Second International Handbook of Science Education. The Netherlands: Springer, 2012b, p. 1041-1060.

ABD-EL-KHALICK, F; LEDERMAN, N. G. The influence of history of science courses on students' views of nature of science. Journal of Research in Science Teaching, v. 37, n. 10, p. 1057-1095, 2000.

ADÚRIZ-BRAVO, A. Una introducción a la naturaleza de la Ciencias. La Epistemología en la enseñanza de las Ciencias Naturales. Buenos Aires: Fondo de Cultura Económica, 2005 .

ADÚRIZ-BRAVO, A. A proposal to teach the nature of science (NOS) to science teachers: The 'structuring theoretical fields' of NOS. Review of Science, Mathematics and ICT Education, v. 1, n. 2, p. 41-56, 2007.

ADÚRIZ-BRAVO, A.; IZQUIERDO, M.; ESTANY, A. Una propuesta para estructurar la enseñanza de la filosofía de la ciencia para el profesorado de ciencias en formación. Enseñanza de las Ciencias, v. 20, n. 3, p. 465-476, 2002. 
ALLCHIN, D. Evaluating knowledge of the nature of (Whole) Science. Science Education, v. 95, n. 3 , p. 518-542, 2011.

ALMEIDA, A. V.; FARIAS, C. R. O. A Natureza da Ciência na Formação de Professores: Reflexões a partir de um curso de Licenciatura em Ciências Biológicas. Investigações em Ensino de Ciências, v. 16, n. 3, p. 473-488, 2011.

BARDIN, L. Análise de Conteúdo. Edição revista e ampliada, São Paulo, Brasil: Edições 70, 2011.

BRASIL. Ministério da Educação. Conselho Nacional de Educação. Parecer CNE/CP 009, de 8 de maio de 2001. Diretrizes Curriculares Nacionais para a Formação de Professores da Educação Básica, em nível superior, curso de licenciatura, de graduação plena. 2001a. Disponível em: <http://portal.mec.gov.br/cne/arquivos/pdf/CES1301.pdf >. Acesso em: 18 nov. 2020.

BRASIL. Ministério da Educação. Conselho Nacional de Educação/Câmara de Educação Superior, Parecer $\mathbf{n}^{\mathbf{0}} \mathbf{1 . 3 0 4} / \mathbf{0 1}$, de 06 de novembro, 2001b. Disponível em: $<$ http://portal.mec.gov.br/cne/arquivos/pdf/CES1304.pdf>. Acesso em: 18 nov. 2020.

BRASIL. Ministério da Educação. Conselho Nacional de Educação. Diretrizes Curriculares Nacionais Gerais da Educação Básica, 2013. Disponível em:

$<$ http://portal.mec.gov.br/index.php?option=com_docman\&view=download\&alias=13448diretrizes-curiculares-nacionais-2013-pdf\&Itemid=30192>. Acesso em: 18 nov. 2020.

BRASIL. Ministério da Educação. Conselho Nacional de Educação/Conselho Pleno, Resolução $\mathbf{n}^{\mathbf{0}}$ 2, de 01 de julho, 2015. Disponível em: $<$ http://portal.mec.gov.br/docman/agosto-2017-pdf/70431-res-cne-cp-002-03072015pdf/file>. Acesso em: 18 nov. 2020.

CARVALHO, A. M. P.; VANNUCCHI, A. O currículo de física: inovações e tendências dos anos noventa. Investigações em Ensino de Ciências, v.X, n.X, 1995. Disponível em: $<$ http://www.if.ufrgs.br/public/ensino/N1/1artigo.htm>. Acesso em: 16 set. 2015.

CLOUGH, M. P. Learners' responses to the demands of conceptual change: considerations for effective nature of science instruction. Science \& Education, v. 15, n. 5, p. 463-494, 2006.

CLOUGH, M. P. Teaching the nature of science to secondary and post-secondary students: Questions rather than tenets. The Pantaneto Forum. 25, 2007. 
CLOUGH, M. P. Teaching and Learning About the Nature of Science. Science \& Education, v. 27, p. 1-5, 2018.

COLL, C. Hacia la elaboración de un modelo de diseño curricular. Cuadernos de Pedagogía, 139, 1986. p. 8-10.

CUTRERA, G. E. La Actividad Científica y la Génesis del Conocimiento Científico en los Textos Escolares de Ciencias Naturales: Un análisis de clasificación. Revista Iberoamericana de Educación, 2003.

DELIZOICOV, D. Editorial. Caderno Catarinense de Ensino de Física, v. 13, n. 3, 182183, dez. 1996.

DELIZOICOV, D. Docência no ensino superior e a potencialização da pesquisa em Educação em Ciências. In: GARCIA, N. M. D et al. (Orgs.) A pesquisa em Ensino de Física e a sala de aula: articulações necessárias. São Paulo : Editora Livraria da Física, 2012. p. 215-226.

DRIVER, R. H. et al. Young people's images of science. Buckingham: Open University Press, 1996.

DUARTE, M. C. A história da ciência na prática de professores portugueses: implicações para a formação de professores de ciências. Ciência \& Educação, v. 10, n. 3, p. 317-331, 2004.

DUSCHL, R. A.; GRANDY, R. Two views about explicitly teaching Nature of Science. Science \& Education, v. 22, n. 9, p. 2109-2139, 2013.

EL-HANI, C. N. Notas sobre o ensino de história e filosofia da ciência na educação científica de nível superior. In: SILVA, C. C. (Org.). Estudos de história e filosofia das ciências: subsídios para aplicação no ensino. São Paulo: Editora Livraria da Física, 2006. cap. 1, p. 321.

FERREIRA, G. K. Reflexões sobre a natureza da ciência: configurações e intenções na formação de professores de física. 2018. 363 f. Tese (Doutorado em Educação Científica e Tecnológica) - Universidade Federal de Santa Catarina, Florianópolis.

FERREIRA, G. K.; CUSTÓDIO, J. F. Reflexões sobre a Natureza das Ciências nos Cursos de Licenciatura em Física no Brasil: breve retrato das configurações atuais. Enseñanza de las ciencias: revista de investigación y experiencias didácticas, v. n. extr, p. 3677-3681, 2017. 
FERREIRA, J. M. H.; MARTINS, A. F. P. Avaliando a inserção da temática natureza da ciência na disciplina de história e filosofia da ciência para graduandos em Física da UFRN. In: PEDUZZI, L. Q.; MARTINS, A. F. P.; FERREIRA, J. M. H. (Orgs.). Temas de História e Filosofia da Ciência no Ensino. Natal: EDUFRN, 2012. p. 155-181.

FORATO, T. C. M.; PIETROCOLA, M.; MARTINS, R. A. Historiografia e natureza da ciência na sala de aula. Caderno Brasileiro de Ensino de Física, v. 28, n. 1, p. 27-59, jan. 2011.

FORATO, T. C. M.; BAGDONAS, A.; TESTONI, A. Episódios históricos e natureza da ciência na formação de professores. Enseñanza de las Ciencias, $n^{\circ}$ extraordinário, p 3511$3516,2017$.

GARCÍA-CARMONA, A.; VÁZQUEZ-ALONSO, Á.; MANASSERO-MAS, M. A. Estado actual y perspectivas de la naturaleza de la ciencia: una revisión de las creencias y obstáculos del profesorado. Enseñanza de las Ciencias, v. 29, n. 3, p. 403-412, 2011. Disponível em: $<$ https://doi.org/10.5565/rev/ec/v29n3.443>.

GARCÍA-CARMONA, A.; VÁZQUEZ-ALONSO, Á.; MANASSERO-MAS, M. A. Comprensión de los estudiantes sobre naturaleza de la ciencia: análisis del estado actual de la cuestión y perspectivas. Enseñanza de las Ciencias, v. 30, n. 1, p. 23-34, 2012. Disponível em: $<$ https://doi.org/10.5565/rev/ec/v30n1.442>.

GARCÍA-MARTÍNEZ, Á.; IZQUIERDO-AYMERICH, M. Contribución de la Historia de las Ciencias al desarrollo profesional de docentes universitarios. Enseñanza de las Ciencias, v. 32, n. 1, p. 265-281, 2014.

GATTI, S. R. T.; NARDI, R.; SILVA, D. A história da ciência na formação do professor de Física: subsídios para um curso sobre o tema atração gravitacional visando às mudanças de postura na ação docente. Ciências \& Educação, v. 10, n. 3, p. 491-500, 2004.

GIERE, R. N. Explaining Science: a cognitive approach. Chicago: University of Chicago Press, 1990. 344 p. (Science and Its Conceptual Foundations Series).

GIL, A. C. Como elaborar projetos de pesquisa. 4. ed. São Paulo: Atlas, 2007.

GIL-PÉREZ, D. et al. Para uma imagem não deformada do trabalho científico. Ciência \& Educação, v. 7, n. 2, p. 125-153, 2001. 
HACKING, I. Representar e Intervir: Tópicos Introdutórios de Filosofia e Ciência Natural. Rio de Janeiro: Eduerj, 2012. 406 p.

HARRES, J. B. S. Uma revisão de pesquisas nas concepções de professores sobre a natureza da ciência e suas implicações para o ensino. Investigações em Ensino de Ciências, v. 4, n. 3, 1999. p. 197-211.

IRZIK, G.; NOLA, R. A Family Resemblance Approach to the Nature of Science for Science Education. Science \& Education, v. 20, n. 7-8, p. 591-607, 2011.

LEDERMAN, N. G. Students' and teachers' conceptions of the nature of science: a review of the research. Journal of Research in Science Teaching, v. 29, n. 4, p. 331-359, 1992.

LEDERMAN, N. G. Research on Nature of Science: Reflections on the Past, Anticipations of the Future. Asia-Pacific Forum on Science Learning and Teaching, v. 7, n. 1, 1-11, 2006.

LEDERMAN, N. G. Nature of Science: past, present, and future. In: ABELL, S. K.; LEDERMAN, N. G. (Ed.), Handbook of Research on Science Education, Mahwah, NJ: Lawrence Erlbaum Associates, 2007. p. 831-880.

LEDERMAN, N. G.; ABD-EL-KHALICK, F. Avoiding de-natured science: Activities that promote understandings of the nature of science. In: McCOMAS, W. F. (Ed). The Nature of Science in Science Education: Rationales and Strategies. Dordrecht: Kluwer, 1998. p. 83126.

LEDERMAN, N. G. et al. Preservice teachers' understanding and teaching of nature of science: An intervention study. Canadian Journal of Science, Mathematics, and Technology Education, 1, p. 135-160, 2001.

LEDERMAN, N. G. et al. Views of Nature of Science Questionnaire: Toward Valid and Meaningful Assessment of Learners' Conceptions of Nature of Science. Journal of Research in Science Teaching, v. 39, n. 6, p. 497-521, 2002.

LEDERMAN, N. G.; BARTOS, S. A.; LEDERMAN, J. S. The development, use, and interpretation of Nature of Science assessments. In: MATTHEWS, M. R. (Ed.). International Handbook of Research in History, Philosophy and Science Teaching. The Netherlands: Springer, 2014, p. 971-997. 
LONDERO, L. A História e a Filosofia da Ciência na formação de professores de Física: controvérsias curriculares. História da Ciência e Ensino: construindo interfaces, v. 11, 2015.

LONGINO, H, Cognitive and non-cognitive values in science: rethinking the dichotomy. In: NELSON, L. H.; NELSON, J. (Ed.). Feminism, science and the philosophy of science. Dordrecht: Kluwer Academic Press, 1996. p. 39-58.

MARTINS, A. F. P. História e Filosofia da Ciência no Ensino: Há muitas pedras nesse caminho... Caderno Brasileiro de Ensino de Física, v. 24, n. 1, p. 112-131, ago. 2007.

MARTINS, A. F. P. Natureza da Ciência no ensino de ciências: uma proposta baseada em "temas" e "questões". Caderno Brasileiro de Ensino de Física, v. 32, n. 3, p. 703-737, maio 2015.

MARTINS, R. A. O que é a ciência do ponto de vista da epistemologia? Caderno de Metodologia e Técnica de Pesquisa, v. 9, p. 5-20, 1999.

MATTHEWS, M.R. Science teaching: the role of history and philosophy of science. New York: Routledge, 1994.

MATTHEWS, M. R. História, filosofia e ensino de ciências: a tendência atual de reaproximação. Caderno Catarinense de Ensino de Física, v. 12, n. 3, p. 164-214, jan. 1995.

MATTHEWS, M. R. Changing the focus: from nature of science to features of science. In: KHINE, M. S. (Ed.). Advances in nature of science research. Dordrecht: Springer, 2012. p. $3-26$.

McCOMAS, W. F. Seeking historical examples to illustrate key aspects of the nature of science. Science \& Education, v. 17, n. 2-3, p. 249-263, 2008.

McCOMAS, W. F. Understanding how science works: the nature of science as they foundation for science teaching and learning. The School science review, v. 98, p. 71-76, 2017.

McCOMAS, W. F.; AlmaZROA, H.; ClOUGH, M. The Nature of Science in Science Education: an introduction. Science \& Education, v. 7, n. 6, p. 11-532, 1998. 
McCOMAS, W. F.; CLOUGH, M.; ALMAZROA, H. The role and character of the Nature of Science in Science Education. In: McCOMAS, W. F. (Ed.). The Nature of Science in Science Education: rationales and strategies. The Netherlands: Kluwer, 1998, p. 3-39.

McCOMAS, W. F.; OLSON, J. K. The Nature of Science in international science educational standards documents. In: McCOMAS, W. F. (Ed.). The Nature of Science in Science Education: rationales and strategies. The Netherlands: Kluwer, 1998. p. 41-52.

McCOMAS, W. F.; NOURI, N. The Nature of Science and the Next Generation Science Standards: Analysis and Critique. Journal of Science Teacher Education, v. 27, p. 555-576, 2016.

MOREIRA, M. A.; MASSONI, N. T.; OSTERMANN, F. "História e Epistemologia da Física" na Licenciatura em Física: uma disciplina que busca mudar concepções dos alunos sobre a Natureza da Ciência. Revista Brasileira de Ensino de Física, v. 29, n. 1, 129-134, 2007.

MOURA, C. B. et al. Entre o histórico e o contemporâneo: abordando as práticas científicas em um curso sobre história e filosofia das ciências. Enseñanza de las Ciencias, $\mathrm{n}^{\circ}$ extraordinário, p. 3517-3523, 2017.

NICOLODELLI, D. N. Mapas conceituais como ferramentas para a organização do conhecimento em uma disciplina sobre a história da física. 2011. 206 f. Dissertação (Mestrado em Educação Científica e Tecnológica) - Universidade Federal de Santa Catarina, Florianópolis.

OSBORNE, J. F. et al. What "Ideas-about-Science" should be taught in school science? A Delphi study of the expert community. Journal of Research in Science Teaching, v. 40, n. 7, p. 1-34, 2001.

OSBORNE, J. F. et al. What "Ideas-about-Science" should be taught in school science? A Delphi study of the expert community. Journal of Research in Science Teaching, v. 40, n. 7, p. 692-720, 2003.

PEREIRA, G. J. S. A.; MARTINS, A. F. P. A inserção de disciplinas de conteúdo históricofilosófico no currículo dos cursos de licenciatura em Física e em Química da UFRN: uma análise comparativa. Caderno Brasileiro de Ensino de Física, Florianópolis, v. 28, n. 1, p. 229-258, jan. 2011. 
PRADO, F. D. Experiências Curriculares com História e Filosofia da Física. Caderno Catarinense de Ensino de Física, v. 6, n. especial, p. 9-17, jun. 1989.

RAPOSO, W. L. História e Filosofia da Ciência na Licenciatura em Física, uma proposta de ensino através da pedagogia de projetos. Caderno Brasileiro de Ensino de Física, Florianópolis, v. 31, n. 3, p. 722-738, maio 2014.

RODRÍGUEZ, R. Y. A.; ADÚRIZ-BRAVO, A. Concepciones emergentes de naturaleza de la ciencia para la didáctica de las ciencias. Enseñanza de las Ciencias, n. extraordinário, p. 3499-3504, 2017.

ROSA, K.; MARTINS, M. C. A inserção de História e Filosofia da Ciência no Currículo de Licenciatura em Física da Universidade Federal da Bahia: Uma visão de professores universitários. Investigações em Ensino de Ciências, v. 12, n. 3, p. 321-337, 2007.

RYDER, J. Identifying science understanding for functional scientific literacy. Studies in Science Education, v. 36, n. 1, p. 1-44, 2001.

RYDER, J. School science education for citizenship: strategies for teaching about the epistemology of science. Journal of Curriculum Studies, v. 34, n. 6, p. 637-658, 2002.

SCHWARTZ, R. S.; LEDERMAN, N. G.; CRAWFORD, B. Understanding the nature of science through scientific inquiry: An explicit approach to bridging the gap. Paper presented at the annual meeting of the National Association for Research in Science Teaching, New Orleans, LA, 2000.

SCHWARTZ, R. S.; LEDERMAN, N. G.; CRAWFORD, B. Developing views of nature of science in an authentic context: An explicit approach to bridging the gap between nature of science and scientific inquiry. Science Education, Hoboken, v. 88, n. 4, p. 610-645, 2004.

STAUB DE MELO, A. C. Contribuições da Epistemologia Histórica de Bachelard no Estudo da Evolução dos Conceitos da Óptica. 2005. 199 f. Dissertação (Mestrado em Educação Científica e Tecnológica) - Universidade Federal de Santa Catarina, Florianópolis.

STAUB, A. C.; PEDUZZI, L. O. Q. Diálogo entre história e filosofia da ciência em uma disciplina de evolução dos conceitos da física. In: Encontro Nacional de Pesquisa em Educação em Ciências, 4, 2003, Bauru. Atas... Porto Alegre: s. n., 2004. 
TARDIF, M. Os professores diante do saber: esboço de uma problemática do saber docente. In: TARDIF, M. Saberes Docentes e Formação Profissional. Petrópolis, Rio de Janeiro: Editora Vozes, 2014a. p. 31-55.

TARDIF, M. Saberes profissionais dos professores e conhecimentos universitários: Elementos para uma epistemologia da prática profissional dos professores e suas consequências para a formação docente. In: TARDIF, M. Saberes Docentes e Formação Profissional. Petrópolis, Rio de Janeiro: Editora Vozes, 2014b. p. 245-276.

TOZONI-REIS, M. F. C. Metodologia da Pesquisa. 2. ed. Curitiba: IESDE Brasil S.A., 2010.

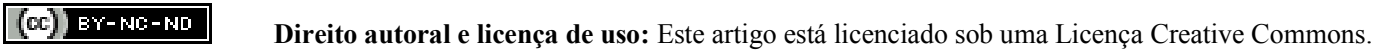

